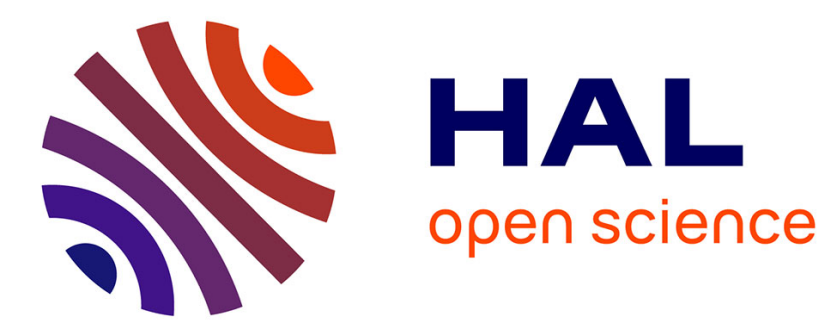

\title{
Experimental and theoretical charge density of DL-alanyl-methionine
}

Régis Guillot, Nicolas Muzet, Slimane Dahaoui, Claude Lecomte, Christian Jelsch

\section{- To cite this version:}

Régis Guillot, Nicolas Muzet, Slimane Dahaoui, Claude Lecomte, Christian Jelsch. Experimental and theoretical charge density of DL-alanyl-methionine. Acta Crystallographica Section B: Structural Science [1968-2013], 2001, B57 (4), pp.567-578. 10.1107/S0108768101007212 . hal-01713040

\author{
HAL Id: hal-01713040 \\ https://hal.science/hal-01713040
}

Submitted on 20 Feb 2018

HAL is a multi-disciplinary open access archive for the deposit and dissemination of scientific research documents, whether they are published or not. The documents may come from teaching and research institutions in France or abroad, or from public or private research centers.
L'archive ouverte pluridisciplinaire HAL, est destinée au dépôt et à la diffusion de documents scientifiques de niveau recherche, publiés ou non, émanant des établissements d'enseignement et de recherche français ou étrangers, des laboratoires publics ou privés. 


\section{Experimental and theoretical charge density of DL-alanyl-methionine Régis Guillot, Nicolas Muzet, Slimane Dahaoui, Claude Lecomte and Christian Jelsch}


Acta Crystallographica Section B

Structural

Science

ISSN 0108-7681

Régis Guillot, Nicolas Muzet, Slimane Dahaoui, Claude Lecomte and Christian Jelsch*

Laboratoire de Cristallographie et Modélisation des Matériaux Minéraux et Biologiques (LCM3B), CNRS UMR 7036, Université Henri Poincaré, Nancy 1, BP 239, 54506 Vandoeuvreles-Nancy CEDEX, France

Correspondence e-mail: jelsch@lcm3b.uhp-nancy.fr

\section{Experimental and theoretical charge density of DL-alanyl-methionine}

X-ray diffraction data up to $d=0.50 \AA$ resolution have been collected at $100 \mathrm{~K}$ for a DL-alanyl-methionine single crystal using a CCD area detector. Multipolar crystallographic refinement was carried out and the electron density of the molecule has been analyzed. The deformation electron density around the $\mathrm{S}$ atom reveals two lone pairs with an $s p^{3}$ hybridization and agrees with the results of density functional theory calculations. The topological properties of the covalent bonds and of the hydrogen bonds have been investigated. Two weak polar intramolecular interactions of the type $\mathrm{C}_{5}$ (pentagonal cyclic structure) have unfavorable geometrical parameters for hydrogen bonds and are devoid of critical points. The two electron lone pairs of the carbonyl oxygen appear asymmetric in the experimental deformation density. This could be attributed to the different strength of the hydrogen bond and intramolecular polar interaction involving the carbonyl oxygen. In the ab-initio-derived deformation maps, the asymmetry of the electron doublets is reproduced only very partially.

\section{Introduction}

The electron density distribution of peptides and amino acids carries information which is important in modeling the interactions between biomolecules. The molecular electrostatic potential and electric moments, which may be derived from the charge density, help to determine the recognition properties of proteins. Furthermore, powerful insights into the nature and strength of hydrogen bonding and ionic interactions result from the analysis of the experimental electron charge density gradient and Laplacian (Bader, 1990; Souhassou \& Blessing, 1999; Espinosa, Lecomte \& Molins, 1999).

Several peptides and amino acids have been analyzed in our laboratory by ultra-high resolution X-ray diffraction (Souhassou et al., 1991, 1992; Wiest et al., 1994; Lecomte, 1995; Pichon-Pesme \& Lecomte, 1998, Pichon-Pesme et al., 2000; Dahaoui, Jelsch et al., 1999; Dahaoui, Pichon-Pesme et al., 1999; Benabicha et al., 2000). In these studies the atomic electron density was described with the most frequently used multipole formalism (Hansen \& Coppens, 1978). Parameters derived from the pseudo-atom multipole model are transferable, at the first order, from one molecule to another (PichonPesme et al., 1995). A database of such parameters derived from X-ray high resolution crystal structures of amino acids and small peptides, transferable to polypeptides and small proteins, has been built. Effective thermal displacement deconvolution and meaningful deformation density distribu-
Received 9 February 2001

Accepted 1 May 2001
(C) 2001 International Union of Crystallography Printed in Great Britain - all rights reserved 
tions can then be achieved for larger structures at lower resolution $(0.6-0.9 \AA)$ by transferring average experimental electron density parameters (Pichon-Pesme et al., 1995; Jelsch et al., 1998, 2000; Housset et al., 2000).

The present paper is devoted to the characterization of the electron density and the topological properties of the dipeptide DL-alanyl-methionine (AlaMet). The analysis focuses on the $\mathrm{C}-\mathrm{S}-\mathrm{C}$ moiety of the methionine side-chain and its properties are compared with the $\mathrm{S}-\mathrm{C}$ group of cystine as recently described by Dahaoui, Pichon-Pesme et al. (1999).<smiles>CSCCC(NC(=O)C([18F])[18F])C(=O)[O-]</smiles>

\section{Materials and methods}

\subsection{Data collection}

The AlaMet compound was purchased from SIGMA (St Louis, USA) and dissolved in an aqueous solution of ammonium hydroxide. Orthorhombic crystals were grown at room temperature by slow evaporation of $\mathrm{NH}_{3}$. A crystal of dimensions $0.52 \times 0.49 \times 0.29 \mathrm{~mm}^{3}$ was selected and cooled to 100 (3) K with a nitrogen vapor open-flow stream device (Oxford Cryosystems cooler 600 series; Cosier \& Glazier, 1986). The crystal was exposed to Mo $K \alpha$ radiation and the Xray diffraction intensities were measured using a Nonius KappaCCD diffractometer. A preliminary short data collection (program COLLECT; Nonius, 1998) to define the best strategy was first performed. The chosen strategy was to fix the kappa angle at the two values of +70 and $-70^{\circ}$ and to take $\omega$ scan measurements. The crystal-to-detector distance was fixed at $45 \mathrm{~mm}$, which gives non-overlapping reflections on the detector while optimizing the two resolution ranges covered. Two batches of data were collected at two detector positions: $\theta=13.4$ and $\theta=26.9^{\circ}$. The exposure times were 30 and $60 \mathrm{~s}$ for the low- and high-resolution frames, respectively. The maximum completeness, given the $2 / m$ Laue group of the crystal, was obtained for each batch using a combination of six $\varphi$ angles $\left( \pm 94, \pm 145\right.$ and $\left.\pm 25^{\circ}\right)$. The scan angle per frame $(\Delta \omega)$ was $1^{\circ}$. The crystal decay was also monitored by repeating the 50 initial frames at the beginning and at the end of each batch. The complete data collection strategy is summarized in Table 1. ${ }^{\mathbf{1}}$ A total of 2977 frames were collected over a period of $5 \mathrm{~d}$.

\subsection{Data reduction}

The intensity integration was performed using DENZO software (Otwinowski \& Minor, 1997). The final unit-cell parameters were refined with the SCALEPACK program

\footnotetext{
${ }^{1}$ Supplementary data for this paper are available from the IUCr electronic archives (Reference: BM0043). Services for accessing these data are described at the back of the journal.
}

Table 1

Experimental details.

\begin{tabular}{|c|c|}
\hline \multicolumn{2}{|l|}{ Crystal data } \\
\hline Chemical formula & $\mathrm{C}_{8} \mathrm{H}_{16} \mathrm{~N}_{2} \mathrm{O}_{3} \mathrm{~S}$ \\
\hline Chemical formula weight & 220.29 \\
\hline Cell setting, space group & Monoclinic, $P 2_{1} / c$ \\
\hline$a, b, c(\AA)$ & $13.089(2), 5.329(1), 15.921(6)$ \\
\hline$\beta\left({ }^{\circ}\right)$ & $108.57(2)$ \\
\hline$V\left(\AA^{3}\right)$ & $1052.7(3)$ \\
\hline$Z$ & 4 \\
\hline$D_{x}\left(\mathrm{Mg} \mathrm{m}^{-3}\right)$ & 1.390 \\
\hline Radiation type & Mo $K \alpha$ \\
\hline $\begin{array}{l}\text { No. of reflections for cell para- } \\
\text { meters }\end{array}$ & 159 \\
\hline$\theta$ range $\left({ }^{\circ}\right)$ & $3.0-19.0$ \\
\hline$\mu\left(\mathrm{mm}^{-1}\right)$ & 0.292 \\
\hline Temperature (K) & $100(5)$ \\
\hline Crystal form, colour & Irregular, colourless \\
\hline Crystal size (mm) & $0.52 \times 0.49 \times 0.29$ \\
\hline \multicolumn{2}{|l|}{ Data collection } \\
\hline Diffractometer & $\begin{array}{l}\text { Nonius Kappa-CCD diffract- } \\
\text { ometer }\end{array}$ \\
\hline Data collection method & Oscillation scans \\
\hline Absorption correction & Empirical \\
\hline$T_{\min }$ & 0.854 \\
\hline$T_{\max }$ & 0.871 \\
\hline $\begin{array}{l}\text { No. of measured, independent and } \\
\text { observed parameters }\end{array}$ & 100 180, 8736, 6979 \\
\hline Criterion for observed reflections & $I>\sigma(I)$ \\
\hline$R_{\text {int }}$ & 0.0490 \\
\hline$\theta_{\max }\left({ }^{\circ}\right)$ & 45.22 \\
\hline Range of $h, k, l$ & $\begin{array}{l}-26 \rightarrow h \rightarrow 26 \\
-10 \rightarrow k \rightarrow 10 \\
-31 \rightarrow l \rightarrow 31\end{array}$ \\
\hline \multicolumn{2}{|l|}{ Refinement } \\
\hline Refinement on & $F^{2}$ \\
\hline$R\left[F^{2}>2 \sigma\left(F^{2}\right)\right], w R\left(F^{2}\right), S$ & $0.0302,0.0253,1.52$ \\
\hline $\begin{array}{l}\text { No. of reflections and parameters } \\
\text { used in refinement }\end{array}$ & 7619,191 \\
\hline $\mathrm{H}$-atom treatment & Mixed \\
\hline Weighting scheme & $\begin{array}{l}w=1 /\left[\sigma^{2}\left(F_{o}^{2}\right)+(0.0605 P)^{2}+\right. \\
\quad 0.0000 P], \text { where } P=\left(F_{o}^{2}+2 F_{c}^{2}\right) / 3\end{array}$ \\
\hline$(\Delta / \sigma)_{\max }$ & 0.001 \\
\hline$\Delta \rho_{\max }, \Delta \rho_{\min }\left(\mathrm{e} \AA^{-3}\right)$ & $0.628,-0.486$ \\
\hline
\end{tabular}

(Otwinowski \& Minor, 1997; HKL data processing system Version 1.11.0) using all the frames collected. The data collection statistics are summarized in Table 1. The scaling of the diffraction frames was performed using the SCALEPACK program. The reflection measurements were merged using the program SORTAV (Blessing, 1997). An empirical absorption correction was applied with SORTAV. The minimum and maximum transmission factors were $T_{\min }=0.854$ and $T_{\max }=$ 0.871 , respectively. The SORTAV program gave 8736 unique structure factor amplitudes to a resolution of $d=0.50 \AA$ with an average redundancy of 11 . The internal agreement factors for all data are given in Table 1.

\subsection{Crystallographic refinement}

The structure was solved using SHELXS86 (Sheldrick, 1990). All the $\mathrm{H}$ atoms were located in difference Fourier maps. A first crystal structure refinement was performed with SHELXL97 (Sheldrick, 1997). The least-squares program MOLLY (Hansen \& Coppens, 1978) was then used to deter- 
mine the charge density of AlaMet. The electron density of the unit cell is described as a superposition of pseudo-atoms described by

$$
\begin{aligned}
\rho(\mathbf{r})= & \rho_{\text {core }}(r)+P_{\text {val }} \kappa^{3} \rho_{\text {val }}(\kappa r) \\
& +\sum_{l=0}^{l_{\max }} \kappa^{\prime 3} R_{n_{l}}\left(\kappa^{\prime} r\right) \sum_{m=0}^{l} P_{l m} y_{l m \pm}(\theta, \varphi),
\end{aligned}
$$

where $\rho_{\text {core }}$ and $\rho_{\text {val }}$ represent the spherical core and valence unitary electron density, respectively. $P_{\text {val }}$ is the valence population parameter and gives an estimate of the net atomic charge $q=N_{\text {val }}-P_{\text {val }}$, where $N_{\text {val }}$ is the number of valence electrons. $y_{l m}$ represent multipolar spherical harmonic functions of the order $l$ in real form, $R_{n l}$ are Slater-type radial functions and $P_{l m}$ are the multipolar populations. The coefficients $\kappa$ and $\kappa^{\prime}$ describe the contraction-expansion for the spherical and multipolar valence densities, respectively. For the $S$ atom, the radial functions used were $n_{l}=4,4,6,8$ and $\alpha=$ 4.1 $\mathrm{Bohr}^{-1}$, as they gave the lowest residual electron density in L-cystine (Dahaoui, Pichon-Pesme et al., 1999). The multipole expansion was truncated at the hexadecapole level for $\mathrm{S}$, and at the octupole level for $\mathrm{O}, \mathrm{N}$ and $\mathrm{C}$ atoms. For the $\mathrm{H}$ atoms only one dipole along the $X-\mathrm{H}$ bond was fitted.

For the structure-factor computations the form factor for the $\mathrm{H}$ atoms was taken from Stewart et al. (1965), the form factors for non-H atoms were calculated from Clementi \& Raimondi (1963), and wave functions and the real and imaginary dispersion corrections to the form factors were from Cromer (1974).

2.3.1. Refinement I. Several refinements were performed and the statistical indexes are given in Table 2. At first, the positional and anisotropic displacement parameters of the non- $\mathrm{H}$ atoms were refined against the reflections with $\sin \theta / \lambda>$ $0.7 \AA^{-1}$ and $I>\sigma(I)$. The positional and isotropic displacement parameters of the $\mathrm{H}$ atoms were then refined against low-order data with $\sin \theta / \lambda<0.7 \AA^{-1}$ and $I>\sigma(I)$. The $\mathrm{H}$ atoms were then displaced by extension along the $\mathrm{Cs} p^{3}-\mathrm{H}$, $\mathrm{Cs} p^{2}-\mathrm{H}, \mathrm{N}^{+}-\mathrm{H}$ and $\mathrm{N}-\mathrm{H}$ axes to bond distances of 1.092, $1.059,1.033$ and $1.009 \AA$, respectively, which are the average values obtained from neutron diffraction (Allen, 1986).

2.3.2. Refinement II. At the beginning of the multipolar refinement, symmetry and chemical constraints were applied to reduce the number of variables. The electron density was constrained to obey local mirror symmetry for the peptide bond, the carboxylate, and the ammonium, $\mathrm{S}, \mathrm{CH}_{2}$ and $\mathrm{CH}_{3}$ moieties. Three types of $\mathrm{H}$ atoms were defined: $\mathrm{HC}$ linked to $\mathrm{Csp}{ }^{3}$ atoms, $\mathrm{HN}^{+}$bound to the ammonium group and $\mathrm{HN}$ bound to the peptide nitrogen. The valence populations $P_{v}$ were constrained to keep the molecule electrically neutral. The refinement was carried out against all the reflections with $I>\sigma(I)$ with the following strategy: $P_{v}+$ scale, $\kappa+$ scale, $\kappa+P_{v}$ + scale, $P_{l m}+$ scale, $\kappa+$ scale and finally $\kappa^{\prime}+$ scale. This process was recycled until convergence was reached.

The chemical and symmetry constraints were then released. The positional and displacement parameters of the non- $\mathrm{H}$ atoms and then the charge density parameters were refined with a similar strategy. As the residual electron density showed
Table 2

Crystallographic refinement statistics.

$s=\sin \theta / \lambda=1 / 2 d ; w=1 / \sigma^{2}\left(\left|F_{o}\right|\right) ; R=\left[\sum_{\mathbf{H}}\left(k\left|F_{o}\right|-\left|F_{c}\right|\right)^{2} / \sum_{\mathbf{H}}\left|F_{o}\right|^{2}\right]^{1 / 2} ; w R=$ $\left(\chi^{2} / \sum \mathbf{H}^{w}\left|F_{o}\right|^{2}\right)^{1 / 2} ; \quad \chi^{2}=\sum w\left(\left|F_{o}\right|-K \mid F_{c}\right)^{2} ;$ goodness-of-fit (g.o.f.) $=$ $\left[\chi^{2} /\left(n_{\mathrm{obs}}-n_{\mathrm{var}}\right)\right]^{1 / 2} ; n_{\mathrm{obs}}$ number of unique reflections used, $n_{\mathrm{var}}$ number of parameters varied.

\begin{tabular}{lllllll}
\hline Refinement & $s\left(\AA^{-1}\right)$ & $R$ & $\mathrm{w} R$ & g.o.f. & $n_{\text {var }}$ & $n_{\text {obs }}$ \\
\hline I & $0.7<s<1.0$ & 0.0421 & 0.0436 & 1.61 & 127 & 4684 \\
& $s<0.7$ & 0.0384 & 0.0427 & 4.23 & 67 & 2935 \\
II & $s<1.0$ & 0.0302 & 0.0253 & 1.52 & 175 & 7619 \\
$\left(\kappa, P_{v}\right)$ & $s<1.0$ & 0.0470 & 0.0612 & 1.98 & 55 & 7619 \\
\hline
\end{tabular}

two positive peaks around the $\mathrm{S}$ atom and as the thermal anisotropy of the $\mathrm{S} 2 D, \mathrm{C} 2 G$ and $\mathrm{C} 2 E$ atoms was relatively high an anharmonic model was applied to these atoms. The only anharmonic parameters significantly higher than their standard deviations were the third-order parameters of the S2D atom, which were retained. A joint high-order GramCharlier and a multipole refinement against all the reflection intensities were described as feasible in the case of an iron porphyrin compound at $0.41 \AA$ resolution; however, the resulting separation of the anharmonicity from the electron density asphericity could not be warranted to be accurate (Mallinson et al., 1988). In the case of AlaMet at $0.5 \AA$ resolution, after a first multipolar refinement, the anharmonicity and the charge density were refined iteratively and it can only be stated that this procedure led to a physically meaningful deformation electron density and a clean residual map around the $\mathrm{S}$ atom. In the residual electron density map computed after the final multipolar refinement [with the reflections $\sin \theta / \lambda$ $<0.9 \AA^{-1}$ and $\left.I>3 \sigma(I)\right]$, the maximum and minimum density

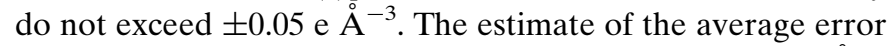
in the experimental difference density maps is $0.04 \mathrm{e}^{-3}$ (Cruickshank, 1949; Rees, 1976).

2.3.3. Kappa refinement. To estimate the atomic charges, a valence population refinement was performed using a spherical atom model (Coppens et al., 1979). In this procedure, only the valence population $P_{v}$ and the expansion/contraction coefficient $\kappa$ were refined, while the multipole populations were reset to and held fixed at zero. The atomic positional and thermal parameters were held fixed at their values from refinement II, as these are their best estimates.

\subsection{Electron-density maps}

The residual and dynamic deformation density maps were computed using 5663 independent reflections with $\sin \theta / \lambda<$ $0.9 \AA^{-1}$ and $I>3 \sigma(I)$. The experimental static deformation density $\Delta \rho$ was computed from the crystallographic modeling as the atomic superposition sum over the molecule

$$
\Delta \rho=\Sigma_{\text {atom }} \rho_{\text {mpa }}-\Sigma_{\text {atom }} \rho_{\text {fra }},
$$

where subscripts mpa and fra represent multipolar atom and free atom, respectively. The static maps correspond to the deformation electron density that would be observed for an immobile molecule $\left(B=0 \AA^{2}\right)$ and were computed directly using the refined values of $X Y Z, P_{l m}, P_{\text {val }}$ and $\kappa, \kappa^{\prime}$ parameters 
Table 3

Selected geometric parameters $\left(\AA,^{\circ}\right)$.

(a) Bond distances $(\AA)$ and angles $\left({ }^{\circ}\right)$ for non-H atoms of AlaMet. The standard uncertainties are given between parentheses.

\begin{tabular}{lllr}
\hline $\mathrm{C} 2-\mathrm{C} 2 A$ & $1.5348(5)$ & $\mathrm{N} 1-\mathrm{C} 1 A-\mathrm{C} 1 B$ & $109.53(4)$ \\
$\mathrm{C} 1-\mathrm{C} 1 A$ & $1.5260(5)$ & $\mathrm{N} 1-\mathrm{C} 1 A-\mathrm{C} 1$ & $109.57(4)$ \\
$\mathrm{C} 1 A-\mathrm{C} 1 B$ & $1.5260(5)$ & $\mathrm{C} 1 B-\mathrm{C} 1 A-\mathrm{C} 1$ & $109.54(4)$ \\
$\mathrm{C} 2 A-\mathrm{C} 2 B$ & $1.5363(5)$ & $\mathrm{C} 1 A-\mathrm{C} 1-\mathrm{O} 1$ & $121.37(4)$ \\
$\mathrm{C} 2 B-\mathrm{C} 2 G$ & $1.5211(5)$ & $\mathrm{C} 1 A-\mathrm{C} 1-\mathrm{N} 2$ & $114.39(4)$ \\
$\mathrm{C} 2-\mathrm{O} 21$ & $1.2567(5)$ & $\mathrm{O} 1-\mathrm{C} 1-\mathrm{N} 2$ & $124.12(4)$ \\
$\mathrm{C} 2-\mathrm{O} 22$ & $1.2580(5)$ & $\mathrm{C} 2 A-\mathrm{C} 2 B-\mathrm{C} 2 G$ & $113.11(4)$ \\
$\mathrm{C} 1-\mathrm{O} 1$ & $1.2402(5)$ & $\mathrm{N} 2-\mathrm{C} 2 A-\mathrm{C} 2$ & $109.39(4)$ \\
$\mathrm{C} 1 A-\mathrm{N} 1$ & $1.4807(5)$ & $\mathrm{C} 2 B-\mathrm{C} 2 A-\mathrm{C} 2$ & $111.35(4)$ \\
$\mathrm{C} 1-\mathrm{N} 2$ & $1.3381(5)$ & $\mathrm{C} 2 A-\mathrm{C} 2-\mathrm{O} 21$ & $117.16(4)$ \\
$\mathrm{C} 2 A-\mathrm{N} 2$ & $1.4556(5)$ & $\mathrm{C} 2 A-\mathrm{C} 2-\mathrm{O} 22$ & $118.20(4)$ \\
$\mathrm{C} 2 G-\mathrm{S} 2 D$ & $1.8086(6)$ & $\mathrm{O} 21-\mathrm{C} 2-\mathrm{O} 22$ & $124.63(4)$ \\
$\mathrm{C} 2 E-\mathrm{S} 2 D$ & $1.8017(6)$ & $\mathrm{C} 2 B-\mathrm{C} 2 G-\mathrm{S} 2 D$ & $109.93(4)$ \\
& & $\mathrm{C} 2 G-\mathrm{S} 2 D-\mathrm{C} 2 E$ & $98.75(4)$ \\
& & &
\end{tabular}

(b) Selected torsion angles in AlaMet.

\begin{tabular}{llr}
\hline & Designation & \multicolumn{1}{c}{ Angle $\left(^{\circ}\right)$} \\
\hline $\mathrm{N} 1-\mathrm{C} 1 A-\mathrm{C} 1-\mathrm{N} 2$ & $\psi$ & $-150.86(12)$ \\
$\mathrm{C} 1 A-\mathrm{C} 1-\mathrm{N} 2-\mathrm{C} 2 A$ & $\omega$ & $-173.53(12)$ \\
$\mathrm{C} 1-\mathrm{N} 2-\mathrm{C} 2 A-\mathrm{C} 2$ & $\varphi$ & $-152.45(13)$ \\
$\mathrm{N} 2-\mathrm{C} 2 A-\mathrm{C} 2 B-\mathrm{C} 2 G$ & $\chi$ & $69.34(14)$ \\
\hline
\end{tabular}

describing the molecular charge density in (1). Obtaining the static density maps necessitates the deconvolution of the thermal motion from the electron density and thus relies on the model of the thermal motion being correct.

\subsection{DFT calculations}

$A b$ initio calculations were performed using the SIESTA code (Sanchez-Portal et al., 1997) with the numerical atomic orbital method for linear-scaling Density Function Theory (DFT; Ordejon et al., 1996; Artacho et al., 1999). Core electrons were replaced by scalar-relativistic norm-conserving pseudopotentials (Troullier \& Martins, 1991) in their fully non-local formulation (Kleinman \& Bylande, 1982). Valence electrons were described using a basis set of finite-range numerical atomic orbitals. They are based on the scheme of pseudo-atomic orbitals of Sankey \& Niklewski (1989; Sanchez-Portal et al., 1996), but generalized to arbitrarily complete bases with double- $\zeta$ polarization orbitals. The generalized gradient approximation (GGA; Perdew et al., 1996) of Kohn-Sham (Kohn \& Sham, 1965) theory was used for exchange and correlation. A uniform mesh with a planewave cutoff of $100 \mathrm{Ry}$ was used to represent the Hartree and exchange-correlation potentials and the local part of the pseudopotential.

This method has been applied to a large variety of systems, from carbon nanotubes, silicon surfaces and nucleic acids (Artacho et al., 1999) to the protein crambin (Fernandez-Serra et al., 2000). A double- $\zeta$ singly polarized basis set (DZP) with large cut-off was used, as it has been shown to give consistent theoretical deformation density maps in good agreement with experimental maps (Fernandez-Serra et al., 2000). The orbital confinement energy shift is equal to $0.14 \mathrm{meV}$ and defines the
$R_{c}$ cut-off radius above which the orbitals are equal to zero. $R_{c}$ values are different for each atom and orbital and are between 5.5 and $9 \AA$. The AlaMet coordinates used were taken from the current crystallographic refinement. Calculations were performed on an AlaMet tetramer $(Z=4)$ in the monoclinic periodic medium reproducing the crystal packing of AlaMet in space group $P 2_{1} / c$.

\section{Results and discussion}

\subsection{Structure analysis}

The crystal structure of AlaMet was first determined at room temperature by Stenkamp \& Jensen (1974) to a resolution of $d=0.65 \AA$. The bond lengths, angles and torsion angles of the AlaMet structure at $100 \mathrm{~K}$ (after the multipolar refinement II) are given in Table 3. Compared to the structure at room temperature (Stenkamp \& Jensen, 1974), the unit-cell volume is reduced by $3 \%$. The $a$ and $c$ parameters decrease significantly by 0.23 and $0.12 \AA$, respectively, and the $\beta$ angle increases from $106.87(2)$ to $108.57(2)^{\circ}$ (Table 1). The reduction of the unit-cell volume upon cooling to $100 \mathrm{~K}$ partly originates from the $\mathrm{N} 1-\mathrm{H} 12 \cdots \mathrm{O} 22$ and $\mathrm{N} 1-\mathrm{H} 13 \cdots \mathrm{O} 1$ hydrogen bonds, which are shortened by 0.03 and $0.06 \AA$, respectively (Table 4).

The conformation and thermal motion of the molecule is depicted in Fig. 1. The methionine side chain is the region of the molecule with the highest displacement parameters $\left(U_{\text {eq }}=\right.$ $0.025 \AA^{2}$ ) and the $\mathrm{S}$ atom was modeled with anharmonic thermal motion.

The $\mathrm{C}-\mathrm{S}-\mathrm{C}$ angle of $98.75(4)^{\circ}$ is not significantly different from the average value of $101.6 \pm 2.5^{\circ}$ computed from 546 occurrences of the $\mathrm{Csp} p^{3}-\mathrm{S}-\mathrm{Cs} p^{3}$ fragment in the Cambridge Structural Database (CSD, version of March 2000). The two $\mathrm{C}-\mathrm{S}$ distances in the AlaMet molecule $d(\mathrm{C} 2 G$, $\mathrm{S} 2 D)=1.8086(6) \AA$ and $d(\mathrm{C} 2 E, \mathrm{~S} 2 D)=1.8017(6) \AA$ are in accordance with the average value for the CSD structures, 1.81 $\pm 0.01 \AA$. The values also agree well with the Engh \& Huber

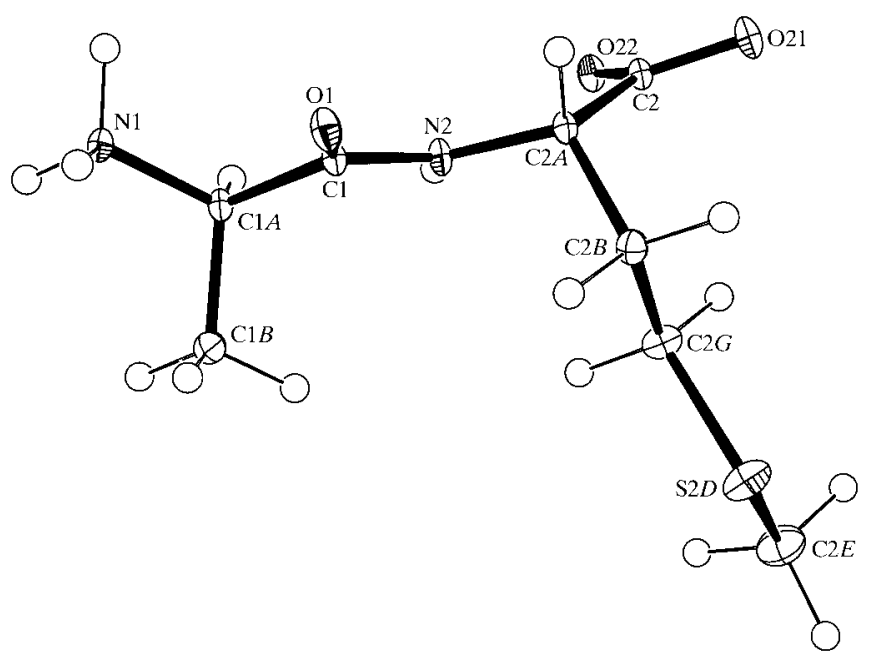

Figure 1

ORTEPIII view (Burnett \& Johnson, 1996) of the AlaMet molecule. Displacement ellipsoids are shown at the $50 \%$ probability level. 
Table 4

Geometrical parameters $\left(\AA,^{\circ}\right)$ of the three intermolecular hydrogen bonds and two intramolecular polar interactions.

The standard uncertainties are given in parentheses. $d(\mathrm{~N} \cdots \mathrm{O}) *$ refers to the structure of Stenkamp \& Jensen (1974) at room temperature.

\begin{tabular}{llllll}
\hline & $\mathrm{N}-\mathrm{H} \cdots \mathrm{O}$ & $d(\mathrm{~N}-\mathrm{H})$ & $d(\mathrm{H} \cdots \mathrm{O})$ & $d(\mathrm{~N} \cdots \mathrm{O})$ & $d(\mathrm{~N} \cdots \mathrm{O})^{*}$ \\
\hline $\mathrm{N} 1-\mathrm{H} 11 \cdots \mathrm{O} 21^{\mathrm{i}}$ & 166.6 & 1.033 & 1.720 & $2.731(1)$ & $2.747(3)$ \\
$\mathrm{N} 1-\mathrm{H} 12 \cdots \mathrm{O} 22^{\mathrm{ii}}$ & 172.2 & 1.038 & 1.802 & $2.834(1)$ & $2.844(3)$ \\
$\mathrm{N} 1-\mathrm{H} 13 \cdots \mathrm{O} 1^{\mathrm{iii}}$ & 146.8 & 1.032 & 2.014 & $2.935(1)$ & $2.983(3)$ \\
$\mathrm{N} 2-\mathrm{H} 2 \cdots \mathrm{O} 22$ & 102.6 & 0.858 & 2.323 & $2.640(1)$ & \\
$\mathrm{N} 1-\mathrm{H} 11 \cdots \mathrm{O} 1$ & 90.5 & 1.033 & 2.584 & $2.787(4)$ & \\
\hline
\end{tabular}

Symmetry codes: (i) $x, \frac{1}{2}-y, z-\frac{1}{2}$; (ii) $x,-\frac{1}{2}-y, z-\frac{1}{2}$; (iii) $-x+1, y-\frac{1}{2}, \frac{3}{2}-z$.

(1991) protein stereochemistry dictionary: angle $(\mathrm{C}-\mathrm{S}-\mathrm{C})=$ $100.9 \pm 2.2^{\circ}, d(\mathrm{C} 2 G, \mathrm{~S})=1.80 \pm 0.04 \AA$ and $d(\mathrm{C} 2 E, \mathrm{~S})=1.79$ $\pm 0.06 \AA$.

The peptide molecules are oriented head-to-tail in chains along the $c$ axis and form a double layer in the $b c$ plane (Fig. 2). In addition to the three intermolecular hydrogen bonds already reported by Stenkamp \& Jensen (1974), there are two weak intramolecular polar interactions in the AlaMet crystal packing (Table 4, Fig. 3). Each $\mathrm{H}$ atom of the ammonium group is involved in one intermolecular interaction, two with the carboxylate group (O21 and O22 of two different peptide molecules) and one with the $\mathrm{O} 1$ carbonyl of another molecule.

The $\mathrm{S}$ atom does not form any hydrogen bonds or polar interactions (Fig. 1). The methionine side chains are arranged such that they are their own nearest neighbors and form a hydrophobic layer parallel to the $c$ axis. This is in accordance with the classification of the methionine as a hydrophobic amino acid (Engelmann et al., 1986). There are six S atoms from symmetry-related molecules within $6 \AA$ of each S atom. The energetically most favorable distance for a $\mathrm{S} \cdots \mathrm{S}$ van der

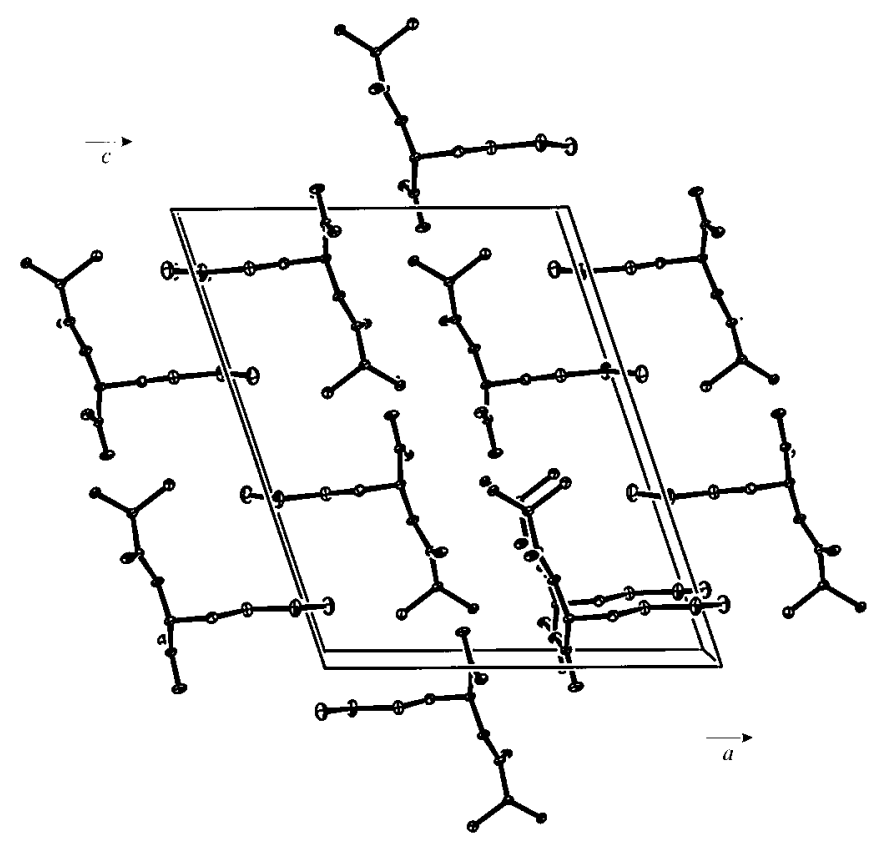

Figure 2

View of the crystal packing in AlaMet.
Waals contact according to the empirical force field of the molecular modeling software AMBER (Bayly et al., 1993, parm94 dictionary) is $4.0 \AA$ (van der Waals interaction energy $-1.047 \mathrm{~kJ} \mathrm{~mol}^{-1}$ ). The shortest $\mathrm{S} . \mathrm{S}$ intermolecular interaction found in AlaMet of 4.37 (1) $\AA$ is larger than this optimal distance and results in an interaction energy of $-0.879 \mathrm{~kJ} \mathrm{~mol}^{-1}$.

\subsection{Deformation electron density}

The experimental static deformation map of the $\mathrm{C} 1=\mathrm{O} 1$ carbonyl group (Fig. 4a) reveals that the $\mathrm{O}$ atom is slightly asymmetric with respect to the two lone pairs (peaks of 0.9 and $0.65 \mathrm{e}^{-3}$ ). The lowest electron doublet forms the weak polar intramolecular interaction $\mathrm{O} 1 \cdots \mathrm{H} 11-\mathrm{N} 1$, while the strongest one is involved in the $\mathrm{O} 1 \cdots \mathrm{H} 13-\mathrm{N} 1$ intermolecular hydrogen bond. The asymmetry of the oxygen electron doublets may be attributed to the different strength of these two polar interactions. The $(\mathrm{N} 1-\mathrm{H} 13 \cdots \mathrm{O} 1)$ atoms form an angle of $147^{\circ}$ and the distance $d(\mathrm{~N} 1, \mathrm{O} 1)=2.93 \AA$ is relatively short, indicating that this geometry is compatible with a hydrogen bond (Table 4), as supported by the results of the topological analysis. The $\mathrm{H} 13$ atom electron density is, however, located significantly outside the peptide bond plane: the $\mathrm{O} 1 \cdots \mathrm{H} 13$ interaction forms a $33^{\circ}$ angle with the peptide plane.

The charge density refined against a previous data set collected in the laboratory on another AlaMet crystal displayed the same dissimilarity of the two electron doublets, the reproducibility of this feature suggesting that it is physically meaningful and is not likely to be the result of systematic errors. The theoretical map in the peptide bond plane (Fig. 4b) does not reproduce this distortion of the deformation density. The two lone pairs of the $\mathrm{O}$ atom are nearly symmetric (maximum deformation density +1.05 e $\AA^{-3}$ ). In some test calculations that have been performed on other interaction geometries, with similar $\mathrm{O}-\mathrm{N}$ distances but with the $\mathrm{H}$ atom located in the peptide bond plane, the two lone pairs do

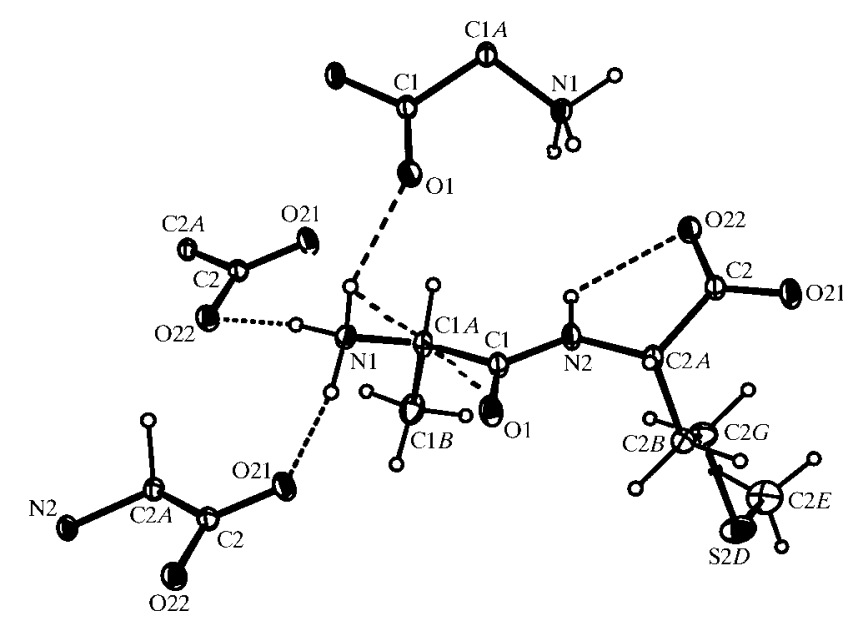

Figure 3

View of the intermolecular hydrogen bonds and intramolecular polar interactions of AlaMet. 
display a stronger asymmetry (Muzet, figures not shown). The distortion of the carbonyl lone pairs was also observed in the calculations on crambin (Fernandez-Serra et al., 2000).

The level of deformation density around the oxygen nucleus appears higher in the theoretical map compared with the experimental map. Notably, the strong electron depletion near the oxygen nucleus on the $\mathrm{O}=\mathrm{C}$ axis in the ab initio map $\left(-0.20\right.$ e $\left.\AA^{-3}\right)$ is almost non-existent in the experimental map. An attenuation of these fine features around the oxygen nucleus in the experimental map was also observed in the case

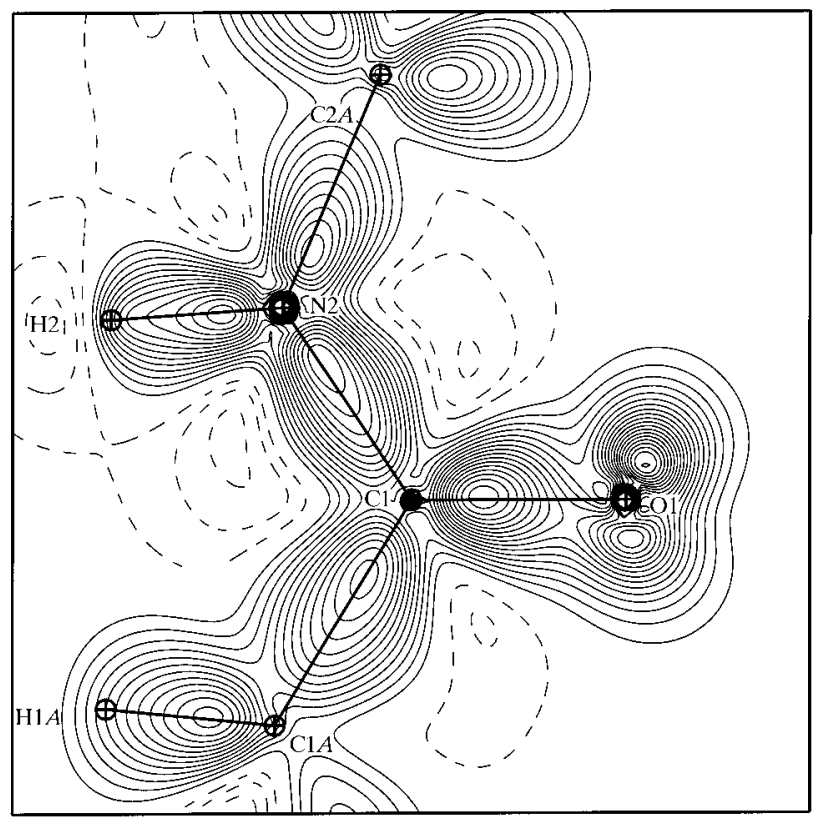

(a)

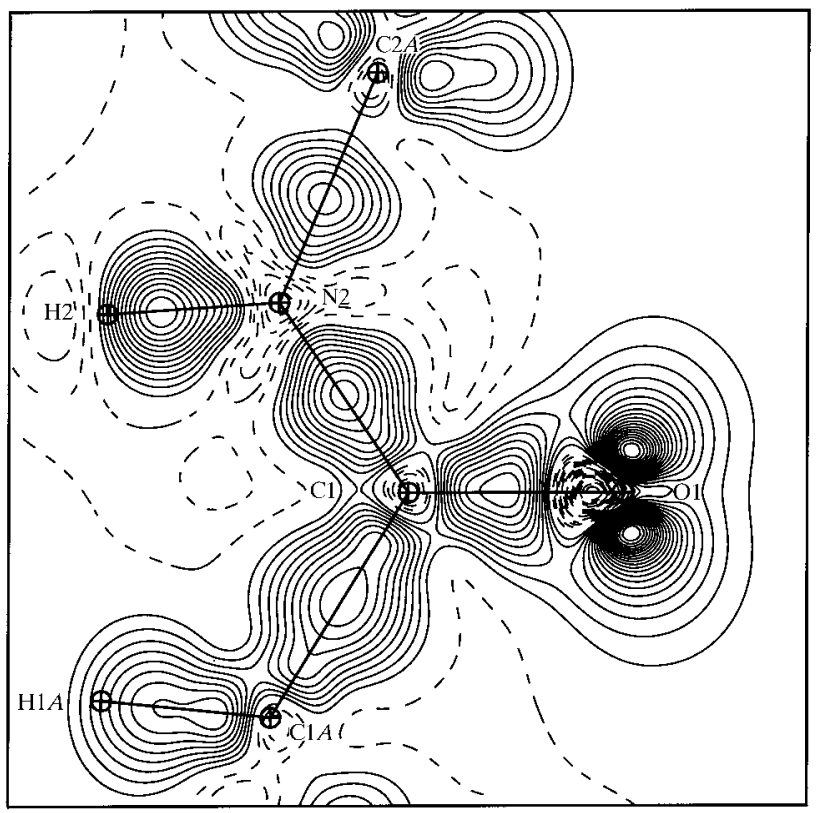

(b)

Figure 4

(a) Experimental and $(b)$ theoretical static deformation electron density in the peptide bond plane. Contour: $+/-0.05$ e $\AA^{-3}$, positive: continuous lines; negative: dashed lines; zero contour omitted.
Table 5

Bond distance, Laplacian and total electron density for the $\mathrm{C}-\mathrm{S}$ bond at the $\mathrm{CP}$ in several charge-density studies.

\begin{tabular}{|c|c|c|c|c|}
\hline \multicolumn{3}{|c|}{ Molecule and reference } & \multirow[b]{2}{*}{$\nabla^{2} \rho\left(\mathrm{e} \AA^{-}\right.$} & \multirow[b]{2}{*}{$\rho\left(\mathrm{e} \AA^{-3}\right)$} \\
\hline $\mathrm{C}-\mathrm{S}$ bon & d-type description and contex & $d(\AA)$ & & \\
\hline \multirow[t]{2}{*}{ AlaMet } & $\mathrm{C} 2 G-\mathrm{S} 2 D \mathrm{CH}_{2}-\mathrm{S}-\mathrm{CH}_{3}$ & $1.8086(6)$ & -4.9 & 1.15 \\
\hline & $\mathrm{C} 2 E-\mathrm{S} 2 \mathrm{DCH}-\mathrm{S}-\mathrm{CH}_{2}$ & $-1.8017(6)$ & -4.7 & 1.22 \\
\hline \multicolumn{5}{|c|}{ BTDMTTF-TCNQ (Espinosa et al., 1997) } \\
\hline $\mathrm{Cs} p^{2}-\mathrm{S}$ & Flat CSCSC ring & 1.747 & -2.39 & 1.33 \\
\hline $\mathrm{Csp}^{3}-\mathrm{S}$ & $\mathrm{CH}_{2}-\mathrm{S}-\mathrm{CH}_{2}-\mathrm{C}-\mathrm{C}$ ring & 1.739 & -3.10 & 1.31 \\
\hline \multicolumn{5}{|c|}{ Diaryl((alkoxy)acyloxy)spiro- $\lambda^{4}$ sulfane (Szabó et al., 1997) } \\
\hline $\mathrm{C}_{\mathrm{ar}}-\mathrm{S}$ & & $1.795(3)$ & -2.60 & 1.36 \\
\hline $\mathrm{C}_{\mathrm{ar}}-\mathrm{S}$ & & $1.789(3)$ & -2.00 & 1.39 \\
\hline \multicolumn{5}{|c|}{ 3,3,6,6-Tetramethyl-S-tetrathiane (McCormack et al., 1996) } \\
\hline $\mathrm{Cs} p^{3}-\mathrm{S}$ & $\mathrm{S}-\left(\mathrm{Csp}{ }^{3}\right)_{2} \mathrm{C}-\mathrm{S}-\mathrm{S}$ & $1.847(1)$ & -6.82 & 1.33 \\
\hline \multicolumn{5}{|c|}{ L-Cystine (Dahaoui, Pichon-Pesme et al., 1999) } \\
\hline $\mathrm{Csp} p^{3}-\mathrm{S}$ & $\mathrm{Csp} p^{3}-\mathrm{CH}_{2}-\mathrm{S}-\mathrm{S}$ & $1.8178(7)$ & -5.68 & 1.21 \\
\hline \multicolumn{5}{|c|}{$p$-(Methylthio)phenynitronyl nitroxide (Pillet et al., 2001) } \\
\hline $\mathrm{C}_{\mathrm{ar}}-\mathrm{S}$ & $\mathrm{C}_{\mathrm{ar}}-\mathrm{S}-\mathrm{CH}_{3}$ & 1.657 & -7.11 & 1.31 \\
\hline $\mathrm{Csp}{ }^{3}-\mathrm{S}$ & $\mathrm{CH}_{3}-\mathrm{S}-\mathrm{C}_{\mathrm{ar}}$ & 1.802 & -5.42 & 1.23 \\
\hline
\end{tabular}

of the protein crambin (Jelsch et al., 2000; Fernandez-Serra et al., 2000). The molecular electron distribution obtained by $a b$ initio Hartree-Fock self-consistent-field molecular orbitals calculations on other peptides (Souhassou et al., 1991, 1992) revealed levels of deformation density in accordance with the present theoretical DFT study.

This discrepancy of the fine features around the oxygen nucleus between experiment and theory could originate from noise or more likely from the limited resolution of the diffraction data. An analysis of the difference between experiment and theory has been performed by Volkov et al. (2000) who also found stronger oxygen lone pairs in the $a b$ initio maps. According to their study, the main origin of the discrepancies may be attributed to the nature of the radial functions used in the experimental multipole model.

\subsection{Electron density and topology of the $S$ atom}

The deformation of the experimental electron density around the $\mathrm{S}$ atom in the CSC plane is shown in Fig. 5(a). The static deformation density reaches $0.25 \mathrm{e}^{-3}$ on the $\mathrm{C} 2 G-$ $\mathrm{S} 2 D(1.809 \AA)$ bond and 0.30 e $\AA^{-3}$ on the $\mathrm{S} 2 D-\mathrm{C} 2 E$ bond

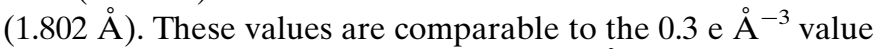
obtained for the $\mathrm{C}-\mathrm{S}$ bond $(d=1.8178 \AA)$ in hexagonal Lcystine (Dahaoui et al., 1999). The experimental map displays a slight asymmetry for the two $\mathrm{C}-\mathrm{S}$ bonds with a larger electron accumulation on the $\mathrm{S} 2 D-\mathrm{C} 2 E$ bond.

The $\mathrm{C}-\mathrm{S}$ interatomic region appears to be a little richer in electrons in the experimental deformation map compared with

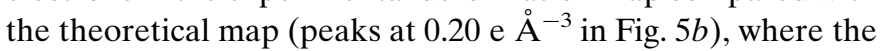
two $\mathrm{C}-\mathrm{S}$ bonds seem to be chemically equivalent. This difference in the experimental map is of a similar level to the error, and it has to be remembered that the thermal motion of the $\mathrm{C} 2 G-\mathrm{S} 2 D-\mathrm{C} 2 E$ group is relatively high and displays some anharmonicity. 
The crystallographic static deformation density map in the bisecting plane of $\mathrm{C} 2 G-\mathrm{S} 2 D-\mathrm{C} 2 E$ (Fig. 6a) reveals the electron sulfur lone pairs with two peaks $\left(0.20\right.$ and 0.25 e $\left.\AA^{-3}\right)$ at a distance of $0.8 \AA$ from the nucleus. The two peaks ( $\mathrm{P} 1$ and $\mathrm{P} 2$ ) are located in the plane bisecting $\mathrm{C}-\mathrm{S}-\mathrm{C}$ and form an angle $\mathrm{P} 1-\mathrm{S}-\mathrm{P} 2$ of $125^{\circ}$, suggesting an $s p^{3}$ hybridization of the $\mathrm{S}$ atoms. The theoretical map in the $\mathrm{C}-\mathrm{S}-\mathrm{C}$ bisecting plane (Fig. $6 b$ ) is consistent with the experimental results and confirms the $s p^{3}$ hybridization of the $\mathrm{S}$ atom. The lone pairs of the $\mathrm{S}$ atom display some asymmetry in the experimental map. In the theoretical map (Fig. $6 b$ ) the asymmetry of the electron

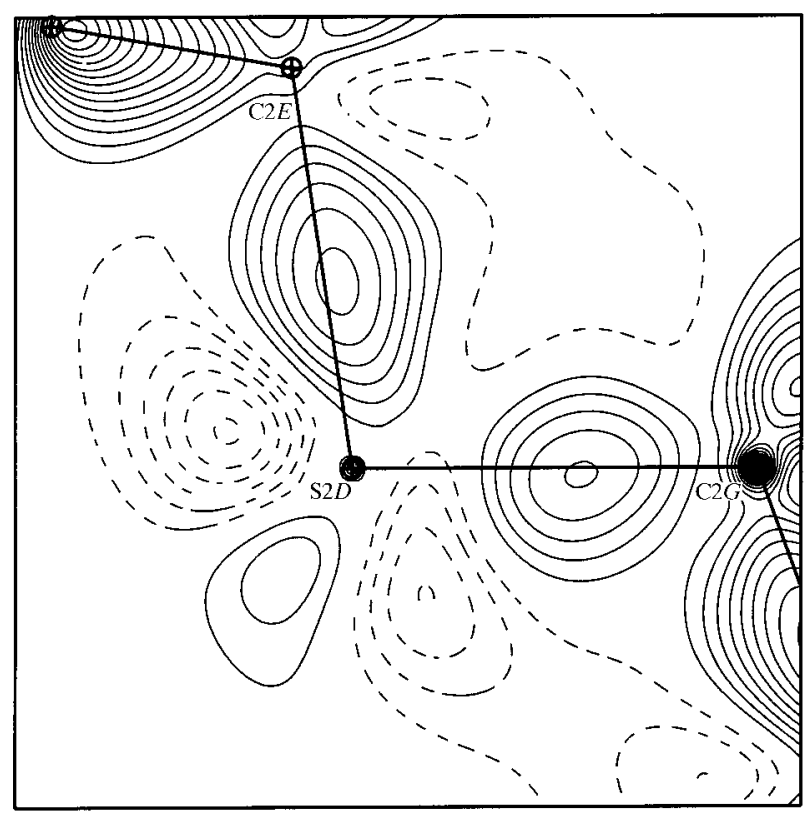

(a)

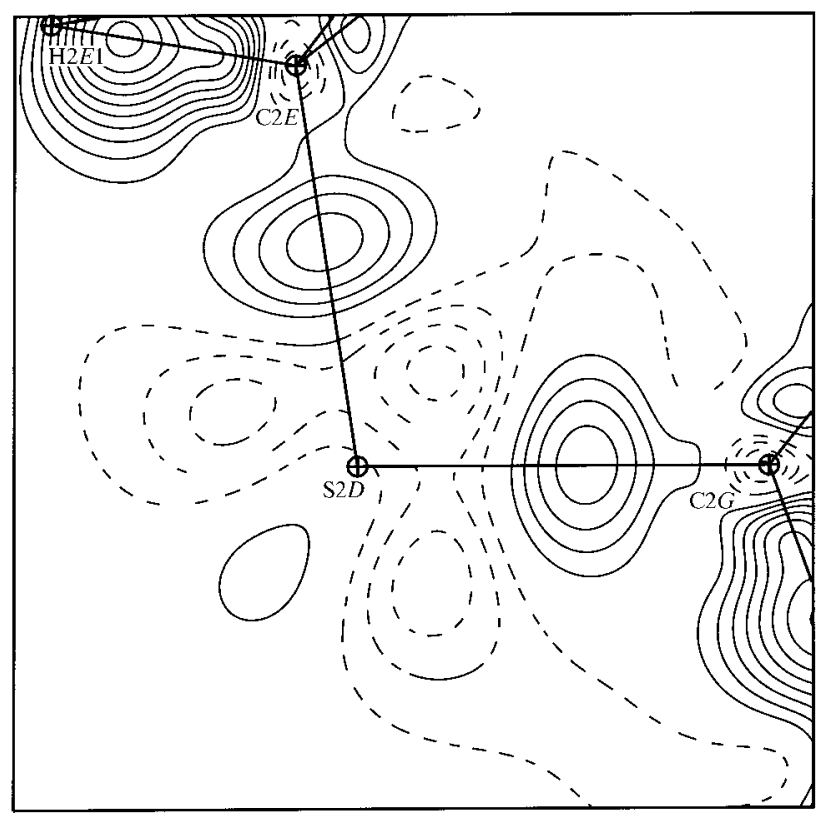

(b)

Figure 5

(a) Experimental and (b) theoretical static deformation electron density in the $\mathrm{C}-\mathrm{S}-\mathrm{C}$ plane. Contour: same as in Fig. 4. doublets is considerably lower, which is entirely consistent with the geometry of the $S$ atom which is only surrounded by methionine side chains at van der Waals distances.

To characterize the chemical bonds, the topology of the experimental electron density has been analyzed using the NEWPROP program (Souhassou \& Blessing, 1999). Figs. 7(a) and $(b)$ display the negative Laplacian in the $\mathrm{C}-\mathrm{S}-\mathrm{C}$ plane and in the plane bisecting the $\mathrm{C}-\mathrm{S}-\mathrm{C}$ group, respectively. The atomic basins are well defined in the methionine $\mathrm{C}-\mathrm{S}-\mathrm{C}$ moiety (Fig. 8). For the $\mathrm{C} 2 G-\mathrm{S} 2 E$ and $\mathrm{S} 2 E-\mathrm{C} 2 E$ bond critical points $(\mathrm{CPs})$, the Laplacian values are -4.8 and -4.7 e $\AA^{-5}$, respectively, the total densities $\rho\left(\mathbf{r}_{c}\right)$ are 1.15 and

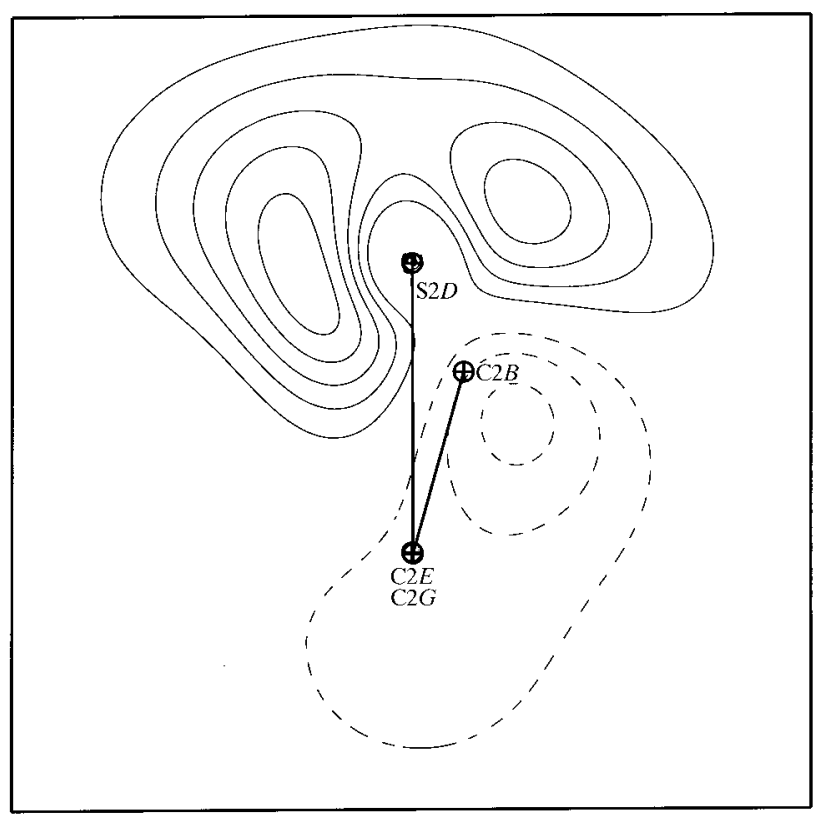

(a)

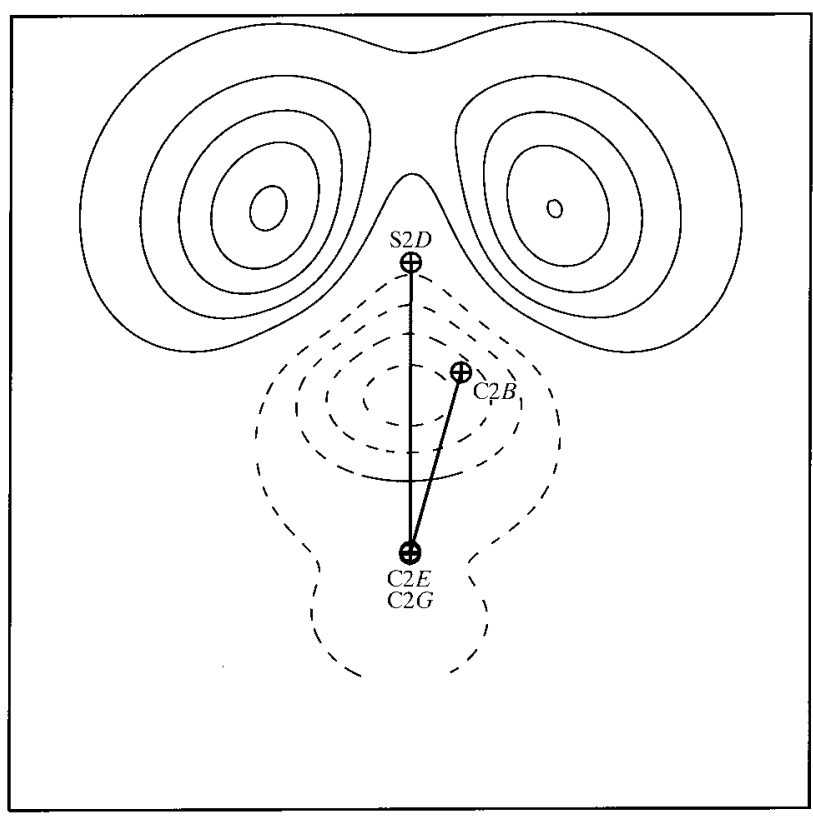

Figure 6

(b)

(a) Experimental and (b) theoretical static deformation electron density in the plane bisecting $\mathrm{C}-\mathrm{S}-\mathrm{C}$. Contour: same as in Fig. 4. 
Table 6

Topological characteristics of the electron density at the covalent bond critical points in AlaMet.

$\rho$ and $\nabla^{2} \rho$ denote the total electron density and its Laplacian at the critical point (CP). $d_{1}$ and $d_{2}$ are the distances from the $\mathrm{CP}$ to the first and the second atom defining the bond, respectively. $d$ is the bond length. The average standard uncertainties of the position and of the density at this critical point are estimated to be approximately $10^{-3} \AA$ and $0.05 \mathrm{e} \AA^{-3}$, respectively. The standard uncertainty on the second derivatives $\Delta \rho$ and $\lambda_{i}$ of the electron density is estimated to be $\sim 10 \%$ of their values (see Espinosa, Souhassou et al., 1999).

\begin{tabular}{llllllllll}
\hline & $d(\AA)$ & $d_{1}(\AA)$ & $d_{2}(\AA)$ & $\rho\left(\mathrm{e}^{-3}\right)$ & Ellipticity & $\nabla^{2} \rho\left(\mathrm{e}^{-5}\right)$ & $\lambda_{1}$ & $\lambda_{2}$ & $\lambda_{3}\left(\mathrm{e}^{-5}\right)$ \\
\hline $\mathrm{C} 1 A-\mathrm{N} 1$ & 1.480 & 0.640 & 0.841 & 1.69 & 0.03 & -8.3 & 14.9 & -11.4 & -11.8 \\
$\mathrm{C} 1-\mathrm{N} 2$ & 1.338 & 0.554 & 0.784 & 2.32 & 0.21 & -21.8 & 15.2 & -16.7 & -20.2 \\
$\mathrm{C} 2 A-\mathrm{N} 2$ & 1.456 & 0.615 & 0.840 & 1.73 & 0.10 & -9.2 & 14.7 & -11.3 & -12.5 \\
$\mathrm{C} 1 B-\mathrm{C} 1 A$ & 1.526 & 0.737 & 0.789 & 1.64 & 0.06 & -10.1 & 10.9 & -10.1 & -10.8 \\
$\mathrm{C} 1 A-\mathrm{C} 1$ & 1.525 & 0.733 & 0.792 & 1.71 & 0.09 & -11.9 & 11.1 & -10.9 & -12.0 \\
$\mathrm{C} 2 B-\mathrm{C} 2 A$ & 1.536 & 0.746 & 0.791 & 1.59 & 0.04 & -10.0 & 10.8 & -10.7 & -10.0 \\
$\mathrm{C} 2 G-\mathrm{C} 2 B$ & 1.521 & 0.733 & 0.789 & 1.65 & 0.05 & -11.2 & 10.2 & -10.4 & -10.9 \\
$\mathrm{C} 2-\mathrm{C} 2 A$ & 1.535 & 0.615 & 0.840 & 1.73 & 0.10 & -12.0 & 10.6 & -10.6 & -12.0 \\
$\mathrm{C} 1-\mathrm{O} 1$ & 1.240 & 0.497 & 0.743 & 2.89 & 0.10 & -29.8 & -21.4 & -24.4 & -26.8 \\
$\mathrm{C} 2-\mathrm{O} 21$ & 1.257 & 0.518 & 0.739 & 2.73 & 0.13 & -26.9 & 21.2 & -22.5 & -25.5 \\
$\mathrm{C} 2-\mathrm{O} 22$ & 1.258 & 0.501 & 0.757 & 2.72 & 0.15 & -27.2 & 21.3 & -22.5 & -25.9 \\
$\mathrm{C} 2 G-\mathrm{S} 2 D$ & 1.809 & 0.862 & 0.947 & 1.15 & 0.15 & -4.9 & 6.9 & -5.4 & -6.3 \\
$\mathrm{C} 2 E-\mathrm{S} 2 D$ & 1.802 & 0.820 & 0.984 & 1.22 & 0.19 & -4.7 & 8.4 & -5.9 & -7.1 \\
\hline
\end{tabular}

concentrated on the $\mathrm{C}-\mathrm{S}$ bond (Table 5). The topological parameters of the $\mathrm{C}-\mathrm{S}$ bonds in AlaMet are listed in Table 5 and are compared to previous studies.

The $\mathrm{C}-\mathrm{S}$ bonds CPs are both slightly closer to the $\mathrm{C}$ atom than to the $\mathrm{S}$ atom: the $d_{1}$ distances $\mathrm{C} 2 E-\mathrm{CP} 1$ and $\mathrm{C} 2 G-\mathrm{CP} 2$ are 20 and $11 \%$, respectively, shorter than the corresponding $d_{2}=\mathrm{CP}-\mathrm{S}$ distances (Table 6, Fig. 7a). This is consistent with the results of cystine (Dahaoui, PichonPesme et al., 1999), for which similar distances were found: $d(\mathrm{~S}-\mathrm{CP})=0.971$ and $d(\mathrm{C}-\mathrm{CP})$ $=0.877 \AA$. The position of the

\section{Table 7}

Expansion/contraction coefficient $\kappa$ and net atomic charges in AlaMet and their standard deviations from the multipolar refinement II and refinement kappa.

Charges from the AMBER molecular modeling dictionary are also given (Bayly et al., 1993). The Mulliken (1955) charges are taken from the DFT calculation with the SIESTA (Sanchez-Portal et al., 1997) package.

\begin{tabular}{|c|c|c|c|c|c|c|}
\hline \multirow[b]{2}{*}{ Atom } & \multicolumn{6}{|c|}{$\kappa$ Net charge $\left(P_{\text {val }}-N_{\text {val }}\right)$} \\
\hline & Ref. kappa & Ref. II & Ref. kappa & Ref. II & AMBER & Mulliken \\
\hline N1 & $1.029(3)$ & $1.012(3)$ & $-0.31(3)$ & $-0.39(3)$ & +0.14 & +0.712 \\
\hline H11 & $1.25(2)$ & $1.17(2)$ & $+0.25(2)$ & $+0.27(2)$ & +0.20 & -0.014 \\
\hline $\mathrm{H} 12$ & $1.29(2)$ & $1.17(2)$ & $+0.24(2)$ & $+0.28(2)$ & +0.20 & -0.018 \\
\hline H13 & $1.28(2)$ & $1.17(2)$ & $+0.24(2)$ & $+0.25(2)$ & +0.20 & -0.016 \\
\hline $\mathrm{C} 1 A$ & $1.032(4)$ & $1.001(4)$ & -0.39 (4) & $-0.23(4)$ & +0.09 & +0.077 \\
\hline $\mathrm{H} 1 A$ & $1.28(2)$ & $1.16(2)$ & $+0.16(2)$ & $+0.16(2)$ & +0.09 & -0.002 \\
\hline$C 1 B$ & $1.022(4)$ & $0.993(4)$ & -0.51 (4) & -0.39 (4) & -0.06 & +0.174 \\
\hline $\mathrm{H} 1 B 1$ & $1.23(2)$ & $1.16(2)$ & +0.15 (2) & $+0.12(2)$ & +0.03 & -0.012 \\
\hline $\mathrm{H} 1 B 2$ & $1.23(2)$ & $1.16(2)$ & +0.09 (2) & $+0.13(2)$ & +0.03 & -0.014 \\
\hline H1B3 & $1.23(2)$ & $1.16(2)$ & $+0.10(2)$ & $+0.12(2)$ & +0.03 & -0.007 \\
\hline $\mathrm{C} 1$ & $1.071(5)$ & $1.007(5)$ & +0.27 (4) & -0.10 & +0.62 & -0.220 \\
\hline O1 & 1.011 & 1.007 (2) & $-0.24(2)$ & $-0.17(2)$ & -0.57 & -0.309 \\
\hline N2 & $1.025(3)$ & $1.010(3)$ & $-0.27(2)$ & $-0.21(2)$ & -0.38 & +0.361 \\
\hline $\mathrm{H} 2$ & $1.25(2)$ & $1.16(2)$ & $+0.26(2)$ & $+0.23(2)$ & +0.13 & -0.052 \\
\hline $\mathrm{C} 2 A$ & $1.039(4)$ & $1.005(4)$ & $-0.36(4)$ & $-0.17(4)$ & -0.26 & +0.099 \\
\hline $\mathrm{H} 2 A$ & $1.23(2)$ & $1.16(2)$ & $+0.07(2)$ & $+0.15(2)$ & +0.13 & +0.002 \\
\hline $\mathrm{C} 2 B$ & $1.026(5)$ & $0.998(5)$ & -0.15 (4) & $-0.26(4)$ & -0.02 & +0.137 \\
\hline $\mathrm{H} 2 B 1$ & $1.27(2)$ & $1.16(2)$ & +0.19 (2) & $+0.18(2)$ & +0.05 & -0.016 \\
\hline $\mathrm{H} 2 B 2$ & $1.27(2)$ & $1.16(2)$ & +0.14 (2) & +0.19 (2) & +0.05 & -0.018 \\
\hline $\mathrm{C} 2 G$ & $0.993(4)$ & 0.985 (4) & -0.65 (4) & -0.41 & +0.05 & +0.199 \\
\hline $\mathrm{H} 2 G 1$ & $1.25(2)$ & $1.16(2)$ & $+0.14(2)$ & $+0.21(2)$ & +0.03 & -0.009 \\
\hline $\mathrm{H} 2 G 2$ & $1.25(2)$ & $1.16(2)$ & $+0.16(2)$ & $+0.17(2)$ & +0.03 & -0.007 \\
\hline $\mathrm{S} 2 D$ & $0.995(5)$ & $1.002(5)$ & $+0.40(6)$ & $-0.03(6)$ & -0.27 & -0.448 \\
\hline $\mathrm{C} 2 E$ & $0.997(4)$ & 0.994 (4) & $-0.45(4)$ & $-0.07(4)$ & -0.04 & +0.223 \\
\hline $\mathrm{H} 2 E 1$ & $1.27(2)$ & $1.18(2)$ & +0.13 & +0.14 & +0.06 & +0.005 \\
\hline $\mathrm{H} 2 E 2$ & $1.27(2)$ & $1.18(2)$ & $+0.26(3)$ & $+0.17(3)$ & +0.06 & +0.006 \\
\hline $\mathrm{H} 2 E 3$ & $1.27(2)$ & $1.18(2)$ & +0.20 & +0.18 & +0.06 & +0.009 \\
\hline $\mathrm{C} 2$ & $1.095(5)$ & 1.018 (5) & $+0.47(2)$ & $+0.00(2)$ & +0.80 & -0.159 \\
\hline $\mathrm{O} 21$ & 0.999 (2) & $1.002(2)$ & $-0.36(2)$ & $-0.22(2)$ & -0.81 & -0.335 \\
\hline $\mathrm{O} 22$ & $1.004(2)$ & $1.002(2)$ & $-0.23(2)$ & $-0.24(2)$ & -0.81 & -0.347 \\
\hline
\end{tabular}

$1.22 \mathrm{e} \AA^{-3}$, and the ellipticities $\varepsilon$ are 0.15 and 0.20 . The values of the density and of its Laplacian are characteristic of a covalent atomic interaction for which the density is slightly
$\mathrm{CP}$ on the bond path depends on the electronegativity and on the atomic number of the two atoms forming the covalent bond. In the case of the $\mathrm{C}-\mathrm{O}$ and $\mathrm{C}-\mathrm{N}$ bonds, the $\mathrm{CP}$ is significantly closer to the $\mathrm{C}$ atom $\left(d_{2} / d_{1}=1.48 \pm 0.04\right.$ and 1.36 \pm 0.04 ; Table 6 ), which can be attributed to the additive effects of the electronegativity and of the larger van der Waals radius of the $\mathrm{O}$ and $\mathrm{N}$ atoms compared to carbon.

The $\mathrm{S}$ atom of the methionine in the present charge density study cannot be considered to be very electronegative as its charge is -0.03 and $+0.40 \mathrm{e}$ after the multipolar and kappa refinements, respectively (Table 7). As a result, the discrepancy between the $\mathrm{C}-\mathrm{CP}$ and $\mathrm{S}-\mathrm{CP}$ distances is not as marked and may essentially be due to the greater radius of the $\mathrm{S}$ atom.

The two $\mathrm{C}-\mathrm{S}$ distances in the AlaMet peptide are closest to the value found in L-cystine (Dahaoui, Pichon-Pesme et al., 1999) and in one of the $\mathrm{C}-\mathrm{S}$ bonds of $p$-(methylthio)phenylnitronyl nitroxide (Pillet et al., 2001). These four bonds with similar topological parameters at the $\mathrm{CP}$ correspond to the $\mathrm{Csp} p^{3}-\mathrm{S}$ type bonds.

The topological analysis of the AlaMet electron density in the $\mathrm{C}-\mathrm{S}-\mathrm{C}$ bisecting plane locates the critical points of the electron lone pairs (Lp) at a distance of $0.9 \AA$ from the nucleus (Fig. $7 b$ ). The Lp1-S2D-Lp2 angle of $125^{\circ}$ is in accordance with $s p^{3}$ hybridization. In the case of L-cystine (Dahaoui, Pichon-Pesme et al., 1999) the corresponding distance and angle are $d=0.7 \AA$ and $145^{\circ}$. We note that the geometrical parameters of these lone pairs determined from the topological analysis are close to those obtained more directly from the static deformation density $\left(d=0.8 \AA\right.$ and angle $=125^{\circ}$, see above).

\subsection{Topology of the covalent bonds}

The topological parameters for the $(3,-1)$ CPs on the covalent bonds (Bader, 1990) are listed in Table 6. For the $\mathrm{C}-$ $\mathrm{C}, \mathrm{C}-\mathrm{N}, \mathrm{C}=\mathrm{O}$ and $\mathrm{C}-\mathrm{O}\left(\mathrm{COO}^{-}\right)$type bonds, the values of 
the total density and of its Laplacian at the CP are in good agreement with the results from other peptides (Benabicha $e t$ al., 2000; Pichon-Pesme et al., 2000; Souhassou \& Blessing, 1999; Coppens et al., 1999; Flaig et al., 1998). In the heteronuclear $\mathrm{C}-\mathrm{N}$ and $\mathrm{C}-\mathrm{O}$ bonds, the bond $\mathrm{CP}$ lies significantly closer to the $\mathrm{C}$ atom, in accordance with a greater accumulation of density concentration in the more electronegative $\mathrm{N}$ or $\mathrm{O}$ atom. In the homonuclear $\mathrm{C}-\mathrm{C}$ bonds, the bond $\mathrm{CP}$ is approximately centered between the two $\mathrm{C}$ atoms.

The bonds with the highest negative Laplacian value at their $\mathrm{CP}$ are located in the $\mathrm{N}-\mathrm{C}=\mathrm{O}$ and $\mathrm{COO}-$ groups, denoting their $\pi$ character (Table 6 ). The peptidic link $\mathrm{C} 1-\mathrm{N} 2$ has a

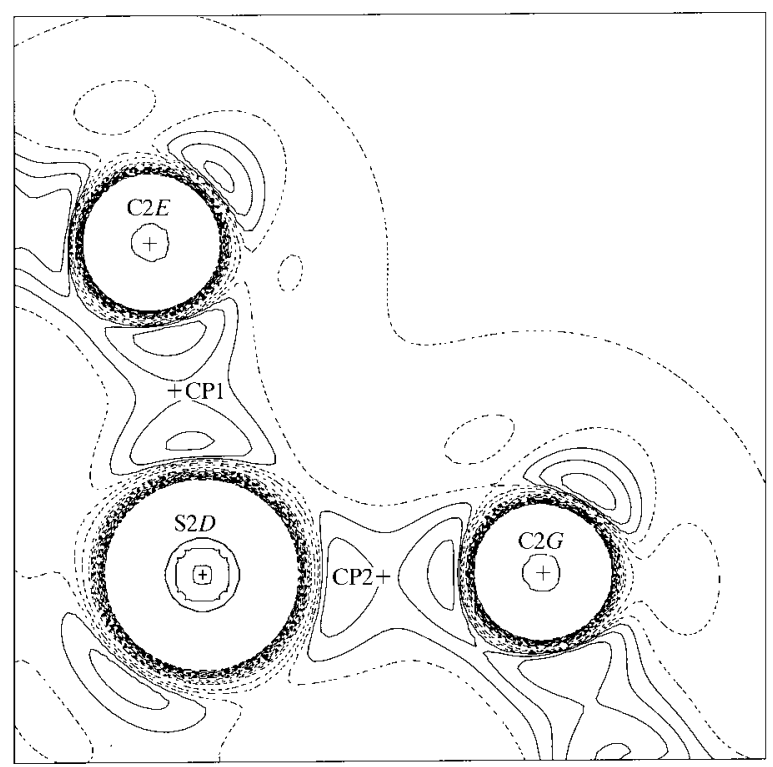

(a)

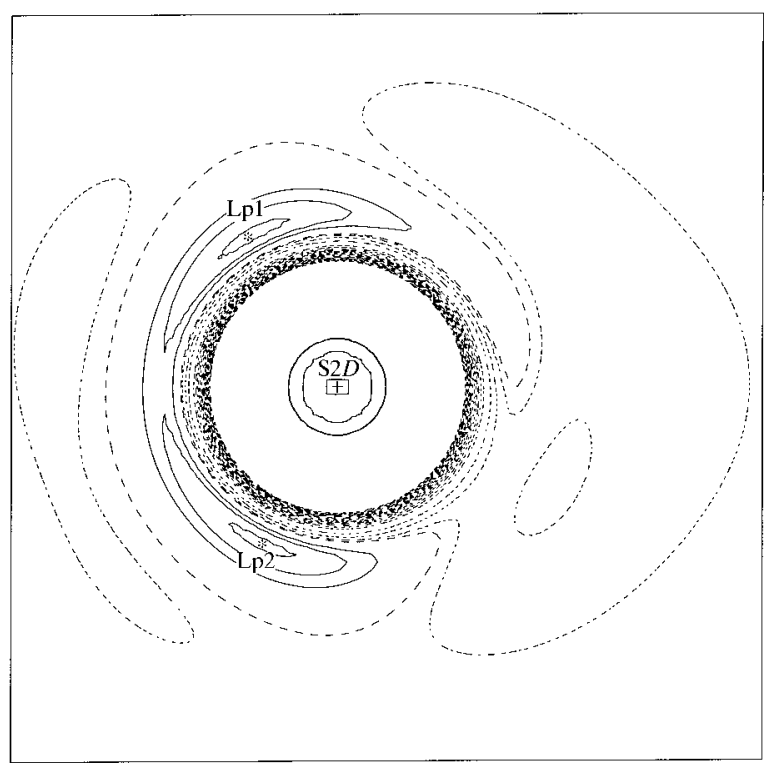

(b)

Figure 7

Negative Laplacian of the electron density $(a)$ in the CSC plane and $(b)$ in the plane bisecting $\mathrm{C}-\mathrm{S}-\mathrm{C}$ (program NEWPROP; Souhassou \& Blessing, 1999). Contour \pm 2 e $\AA^{-5}$. negative Laplacian of $-21.8 \mathrm{e} \AA^{-5}$ at the $\mathrm{CP}$, which is double that of the $\mathrm{C} 1 A-\mathrm{N} 1$ and $\mathrm{C} 2 A-\mathrm{N} 2$ bonds. The total electron density varies concomitantly in almost the same proportions.

The negative Laplacian and the density at the carbonyl $\mathrm{C}=\mathrm{O} \mathrm{CP}$ are, respectively, approximately 10 and $7 \%$ higher than in the carboxylate $\mathrm{C}-\mathrm{O}$ bonds (Table 6). The difference in $\pi$ character of the $\mathrm{C}-\mathrm{O}$ and $\mathrm{C}-\mathrm{N}$ bonds is illustrated by the change in properties of the bond $\mathrm{CP}$. The values of the density and of the negative Laplacian at the CP clearly increase with the $\pi$ character of the bond, while the bond length decreases.

\subsection{Hydrogen-bond topology}

According to the theory of Bader (1990), a good criterion for a polar non-bonded interaction of the type $\mathrm{H} \cdots A$ to be considered as a hydrogen bond is the existence of a CP along the $\mathrm{H} \cdots A$ path. The geometrical parameters of the three intermolecular and of the two intramolecular $\mathrm{N}-\mathrm{H} \cdots \mathrm{O}$ polar interactions are reported in Table 4 . The $\mathrm{N} 2-\mathrm{H} 2 \cdots \mathrm{O} 22-\mathrm{C} 2$ interacting atoms, together with $\mathrm{C} 2 A$, are involved in a pentagonal cyclic structure. This motif, termed the $C 5$ conformation, is the only polar interaction found for example in the structure of the tripeptide described by Aubry et al. (1994). The $\mathrm{N} 1-\mathrm{H} 11 \cdots \mathrm{O} 1-\mathrm{C} 1$ interaction group together with the $\mathrm{C} 1 A$ atom is also in the $C 5$ conformation. The distances $d(\mathrm{~N} 2 \cdots \mathrm{O} 22)=2.63 \AA$ and $d(\mathrm{~N} 1 \cdots \mathrm{O} 1)=2.73 \AA$ are compatible with hydrogen bonding. However, the two intramolecular $\mathrm{N}-\mathrm{H}$... O features turn out to be devoid of CPs, as can be understood from geometrical features. The $\mathrm{N} 2-$ $\mathrm{H} 2 \cdots \mathrm{O} 22$ angle of $102^{\circ}$ is too small and the distance $d(\mathrm{H} 2$, $\mathrm{O} 22)=2.2 \AA$ too large for the interaction to be considered as a hydrogen bond. The geometry of $\mathrm{N} 1-\mathrm{H} 11$. . O 1 is even less

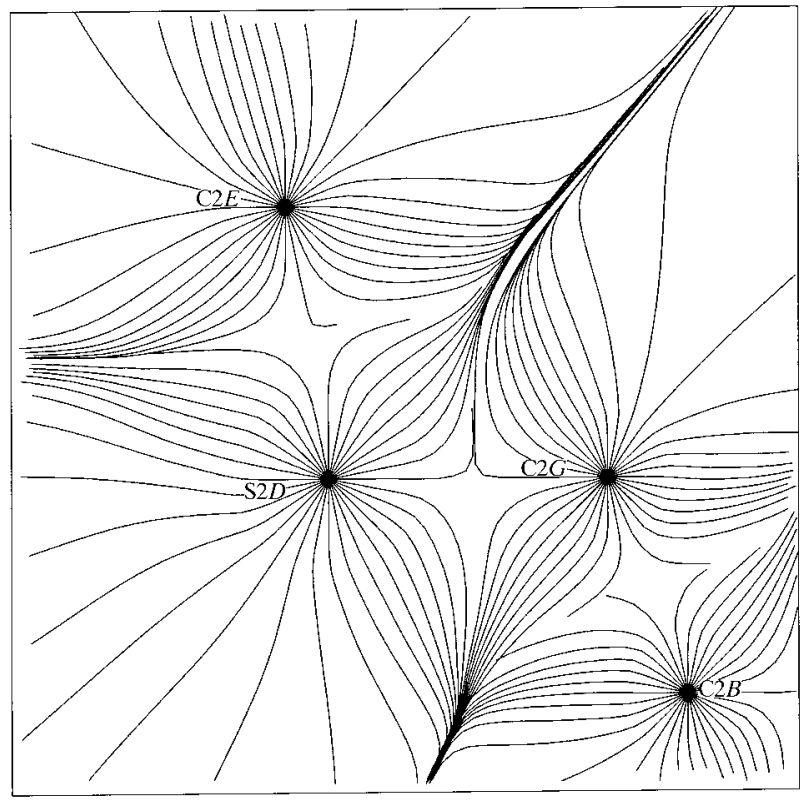

Figure 8

Representation of the gradient lines of the total electron density in the $\mathrm{C}-\mathrm{S}-\mathrm{C}$ plane. 
Table 8

Topological characteristics of the electron density at the critical point of the hydrogen bonds.

\begin{tabular}{lllllll}
\hline & $d(\AA)$ & $d_{1}(\AA)$ & $d_{2}(\AA)$ & $\rho\left(\mathrm{e} \AA^{-3}\right)$ & Ellipticity & $\nabla^{2} \rho\left(\mathrm{e} \AA^{-5}\right)$ \\
\hline $\mathrm{N} 1-\mathrm{H} 11 \cdots \mathrm{O} 21$ & $1.720(4)$ & 0.515 & 1.210 & 0.26 & 0.05 & 4.01 \\
$\mathrm{~N} 1-\mathrm{H} 12 \cdots \mathrm{O} 22$ & $1.802(4)$ & 0.601 & 1.193 & 0.19 & 0.05 & 3.66 \\
$\mathrm{~N} 1-\mathrm{H} 13 \cdots \mathrm{O} 1$ & $2.014(4)$ & 0.763 & 1.272 & 0.11 & 0.19 & 2.02 \\
\hline
\end{tabular}

Table 9

Evaluation of the kinetic density for closed-shell interaction at the critical point.

$G_{1}$ and $G_{2}$ are, respectively, the evaluation of the kinetic energy density for close-shell interactions at the critical point as proposed by Abramov (1997) and Espinosa, Souhassou et al. (1999).

\begin{tabular}{llllll}
\hline & $\lambda_{1}\left(\mathrm{e} \AA^{-5}\right)$ & $\lambda_{2}\left(\mathrm{e} \AA^{-5}\right)$ & $\lambda_{3}\left(\mathrm{e} \AA^{-5}\right)$ & $G_{1}$ (a.u.) & $G_{2}$ (a.u. $)$ \\
\hline $\mathrm{N} 1-\mathrm{H} 11 \cdots \mathrm{O} 21$ & -1.4 & -1.5 & 6.9 & 0.0404 & 0.0402 \\
$\mathrm{~N} 1-\mathrm{H} 12 \cdots \mathrm{O} 22$ & -1.0 & -1.2 & 5.9 & 0.0327 & 0.0344 \\
$\mathrm{~N} 1-\mathrm{H} 13 \cdots \mathrm{O} 1$ & -0.4 & -0.5 & 2.9 & 0.0169 & 0.0169 \\
\hline
\end{tabular}

favorable for a hydrogen bond (Table 4), with a N1 $-\mathrm{H} 1 \cdots \mathrm{O}$ angle of $90^{\circ}$ and a longer distance $d(\mathrm{H}, \mathrm{O})=2.6 \AA$.

In the $a b$ initio study of Popelier \& Bader (1994), the structure of $N$-formyltriglycineamide, optimized in vacuo, does display a $\mathrm{CP}$ on the $\mathrm{O} \cdots \mathrm{H}$ path of a hydrogen bond forming a $C 5$ cycle. In that structure, the distance $d(\mathrm{O}, \mathrm{N})=$ $2.59 \AA$ and the angle $(\mathrm{N}-\mathrm{H} \cdots \mathrm{O})=108.5^{\circ}$ give a slightly more favorable hydrogen-bond geometry compared with AlaMet

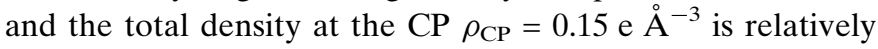
high.

The three intermolecular hydrogen bonds display a signifi-

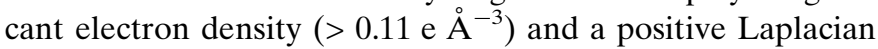
at the CP (Table 8). This is a characteristic of close-shell interactions (Bader, 1990) which are governed by the contraction of the charge density towards each of the interacting nuclei. Among the three intermolecular hydrogen bonds on the ammonium group, the $\mathrm{N} 1-\mathrm{H} 13 \ldots \mathrm{O} 1$ interaction is the weakest and the bond distance $d(\mathrm{~N} \cdots \mathrm{O})=2.935$ (1) is the longest. The level of the electron density and of the Laplacian at this hydrogen bond $\mathrm{CP}$ are indeed approximately half that of either of the two strong intermolecular hydrogen bonds (Table 8).

The $\lambda_{3}$ curvature of the density in the direction along the bond path turns out to be dominant (Table 9). In previous studies (Abramov, 1997; Espinosa et al., 1998; Espinosa, Lecomte \& Molins, 1999; Espinosa, Souhassou et al., 1999), the relationship between the energetic properties of the hydrogen bond interaction and the topological overlapping of the electronic clouds at the $\mathrm{H} \cdots \mathrm{O} \mathrm{CP}$ has been investigated. One of the most interesting results is the linear correlation between the $\lambda_{3}$ curvature and the kinetic energy density $G$ at the CP: $G$ $=a \lambda_{3}$, where $a=15.3 \AA^{5} \mathrm{~kJ} \mathrm{e}^{-1} \mathrm{~mol}^{-1}$, according to Espinosa, Souhassou et al. (1999). The $G$ values obtained for the three hydrogen bonds in AlaMet (Table 9) are in very good agreement with this formula as well as those calculated using the equation of Abramov (1997).

\subsection{Atomic charges}

The expansion/contraction coefficient $\kappa$ and the net atomic charges after the $\left(\kappa, P_{v}\right)$ spherical refinement (Coppens et al., 1979) are listed in Table 7. For $\mathrm{H}$ atoms linked to the same atom type, the $\kappa$ parameters were constrained to be identical, except for the ammonium group which is involved in three hydrogen bonds. The net atomic charges can also be obtained from the molecular orbital calculations based on the Mulliken Population Analysis (MPA). These theoretical charges are also reported, although the comparison between MPA and other methods is known to have severe limitations.

Charges of opposite sign $(-0.12 \mathrm{e}$ and $+0.42 \mathrm{e})$ appear on the $\mathrm{COO}^{-}$and $\mathrm{NH}_{3}^{+}$groups, respectively, after the $\left(\kappa, P_{v}\right)$ refinement. The carboxylate and ammonium charges of the zwitterionic AlaMet molecule appear smaller compared with those found in the same groups of Leu-enkephaline: $-0.88 \mathrm{e}$ and $+0.88 \mathrm{e}$ (Wiest et al., 1994), L-arginine phosphate: $-0.67 \mathrm{e}$ and $+0.57 \mathrm{e}$ (Espinosa et al., 1996), L-glycyl-aspartic acid: $-0.66 \mathrm{e}$ and $+0.48 \mathrm{e}$, L-tyrosyl-glycine-glycine: $-0.37 \mathrm{e}$ and $+0.40 \mathrm{e}$ (Pichon-Pesme et al., 2000), L-cystine: $-0.38 \mathrm{e}$ and $+0.45 \mathrm{e}$ (Dahaoui, Pichon-Pesme et al., 1999) and glycyl-L-threonine (Benabicha et al., 2000) $-0.52 \mathrm{e}$ and +0.31 e. The charges on the carboxylate and ammonium groups $(-0.82 \mathrm{e}$ and $+0.74 \mathrm{e}$, respectively) in the AMBER dictionary (Bayly et al., 1993), obtained by fitting of the theoretical potential, are larger than those derived from the X-ray experiments.

The $S$ atom has a charge of $-0.03 \mathrm{e}$ and $+0.40 \mathrm{e}$ after the multipolar and kappa refinements, respectively (Table 7). The experimental atomic charges derived from the multipolar refinement II for the $-\mathrm{CH}_{2}-\mathrm{S}-\mathrm{CH}_{3}$ methionine side chain are generally in better accordance with the AMBER dictionary than those derived from the kappa refinement.

The molecular dipole moment calculated with the multipolar model (refinement II) and with the net atomic charges derived from the kappa refinement (Coppens et al., 1979) are 10.0 (5) and 6.2 (5) Debye, respectively. For comparison, the dipole moment calculated with the AMBER charges is 10.2 Debye.

\section{Conclusions}

This crystallographic investigation has provided detailed information about the electron distribution in the AlaMet peptide. Analysis of this peptide containing the methionine amino acid was performed to complete the databank of multipolar parameters (Pichon-Pesme et al., 1995) describing the charge density of peptides and proteins. A quantitative characterization of the covalent bonds and of the hydrogen bonds has been obtained through the topological analysis of the total electron density. The basis set used in the current $a b$ initio calculations was calibrated according to the experimental electron density. The theoretical and crystallographic 
maps are in good agreement for the $\mathrm{S}$ atom, as well as the $\mathrm{N}, \mathrm{C}$ and $\mathrm{H}$ atoms.

The lone pairs of the $\mathrm{O}$ atoms are, however, systematically stronger in the theoretical maps compared with the experimental maps, as already observed in other studies. This is presumably due to the limited X-ray resolution and to the functions used to fit the experimental density (Volkov et al., 2000). Further investigations of the basis sets used for the $O$ atom in the SIESTA (Sanchez-Portal et al., 1997) program might also be necessary to understand the discrepancies with the experiment.

According to the experimental deformation density, polar interactions such as hydrogen bonds have a distorting effect on the electron cloud in the region of the oxygen lone pairs. Additional charge density analyses on other small molecules using a combination of theory and experiment are deemed necessary to calibrate the distortion of the oxygen electron doublets with respect to the geometry of the hydrogen bond(s).

Pr. Emilio Artacho and Maria Victoria Fernandez-Serra are gratefully acknowledged for helpful discussions on the SIESTA program. NM was supported by a grant of the Association pour la Recherche sur le Cancer and RG by a fellowship of the French Minister of Research and Technology.

\section{References}

Abramov, Yu. A. (1997). Acta Cryst. A53, 264-272.

Allen, F. (1986). Acta Cryst. B42, 515-522.

Artacho, E., Sanchez-Portal, D., Ordejon, P., Garcia, E. \& Soler, J. M. (1999). Phys. Status Solidus B, 215, 809-817.

Aubry, A., Del Luca, V., Pantano, M., Formaggio, F., Crisma, M., Toniolo, C. \& Kamphuis, J. (1994). Lett. Pept. Sci. 1, 157-162.

Bader, R. F. W. (1990). Atoms in Molecules: A Quantum Theory, The International Series of Monographs of Chemistry, edited by J. Halpen and M. L. H. Green. Oxford: Claredon Press.

Bayly, C. I., Cieplack, P., Cornell, W. D. \& Kollman, P. A. (1993). J. Phys. Chem. 97, 10269-10280.

Benabicha, F., Pichon-Pesme, V., Jelsch, C., Lecomte, C. \& Khmou, A. (2000). Acta Cryst. B56, 155-165.

Blessing, R. H. (1997). J. Appl. Cryst. 30, 421-426.

Burnett, M. N. \& Johnson, C. K. (1996). ORTEPIII. Report ORNL6895. Oak Ridge National Laboratory, Tennessee, USA.

Clementi, E. \& Raimondi, D. L. (1963). J. Chem. Phys. 41, 2686-2689.

Coppens, P., Abramov, Y., Carducci, M., Korjov, B., Novozhilova, I., Alhambra, C. \& Pressprich, M. R. (1999). J. Am. Chem. Soc. 121, 2585-2593.

Coppens, P., Guru Row, T. N., Leung, P., Stevens, E. D., Becker, P. J. \& Yang, Y. W. (1979). Acta Cryst. A35, 63-72.

Cosier, J. \& Glazier, A. M. (1986). J. Appl. Chem. 19, 105-107.

Cromer, D. T. (1974). International Tables for X-ray Crystallography, edited by J. A. Ibers and W. E. Hamilton, pp. 148-151. Birmingham: Kynoch Press.

Cruickshank, D. W. J. (1949). Acta Cryst. 2, 65-82.

Dahaoui, S., Jelsch, C., Howard, J. A. K. \& Lecomte, C. (1999). Acta Cryst. B55, 226-230.

Dahaoui, S., Pichon-Pesme, V., Howard, J. A. K. \& Lecomte, C. (1999). J. Phys. Chem. A, 103, 6240-6250.

Engelmann, D. M., Steitz, T. A. \& Goldmann, A. (1986). Ann. Rev. Biophys. Chem. 15, 330-353.
Engh, R. A. \& Huber, R. (1991). Acta Cryst. A47, 392-400.

Espinosa, E., Lecomte, C. \& Molins, E. (1999). Chem. Phys. Lett. 300, 745-748.

Espinosa, E., Lecomte, C., Molins, E., Veintemillas, S., Cousson, A. \& Paulus, W. (1996). Acta Cryst. B52, 519-534.

Espinosa, E., Molins, E. \& Lecomte, C. (1997). Phys. Rev. B, 56, 18201833.

Espinosa, E., Molins, E. \& Lecomte, C. (1998). Chem. Phys. Lett. 285, 170-173.

Espinosa, E., Souhassou, M., Lachekar, H. \& Lecomte, C. (1999). Acta Cryst. B55, 563-572.

Fernandez-Serra, M. V., Junquera, J., Jelsch, C., Lecomte, C. \& Artacho, E. (2000). Solid State Commun. 116, 395-400.

Flaig, R., Koritsansky, D., Zobel, D. \& Luger, P. (1998). J. Am. Chem. Soc. 120, 2227-2238.

Hansen, N. K. \& Coppens, P. (1978). Acta Cryst. A34, 909-921.

Housset, D., Pichon-Pesme, V., Jelsch, C., Benabicha, F., Maierhofer, A., David, S., Fontecilla-Camps, J. C. \& Lecomte, C. (2000). Acta Cryst. D56, 151-160.

Jelsch, C., Pichon-Pesme, V., Lecomte, C. \& Aubry, A. (1998). Acta Cryst. D54, 1306-1318.

Jelsch, C., Teeter, M. M., Lamzin, V., Pichon-Pesme, V., Blessing, R. H. \& Lecomte, C. (2000). Proc. Natl. Acad. Sci. USA, 97, 31713176.

Kleinman, L. \& Bylande, D. M. (1982). Phys. Rev. Lett. 48, 1425-1428.

Kohn, W. \& Sham, J. (1965). Phys. Rev. 140, 1133-1138.

Lecomte, C. (1995). Advances in Molecular Structure Research, edited by I. Hargittai and M. Hargittai, Vol. 1, pp. 261-302. Greenwich, CT, USA: JAI Press Inc.

Mallinson, P. R., Koritsanszky, T., Elkaim, E., Li, N. \& Coppens, P. (1988). Acta Cryst. A44, 336-342.

McCormack, K. L., Mallinson, P. R., Webster, B. C. \& Yufit, D. S. (1996). J. Chem. Soc. Faraday Trans. 92, 1709-1716.

Mulliken, R. S. (1955). J. Chem. Phys. 23, 1833-1846.

Nonius (1998). Collect. Nonius BV, Delft, The Netherlands.

Ordejon, P., Artacho, E. \& Soler, J. M. (1996). Phys. Rev. B, 53, 10441-10444.

Otwinowski, Z. \& Minor, W. (1997). Methods in Enzymology, Vol. 276, Macromolecular Crystallography, part A, edited by C. W. Carter and R. M. Sweet, pp. 307-326. New York: Academic Press.

Perdew, J. P., Burke, K. \& Ernzerhof, M. (1996). Phys. Rev. Lett. 77, 3865-3868.

Pichon-Pesme, V., Lachekar, H., Souhassou, M. \& Lecomte, C. (2000). Acta Cryst. B56, 728-737.

Pichon-Pesme, V. \& Lecomte, C. (1998). Acta Cryst. B54, 485-493.

Pichon-Pesme, V., Lecomte, C. \& Lachekar, H. (1995). J. Phys. Chem. 99, 6242-6250.

Pillet, S., Souhassou, M., Pontillon, Y., Caneschi, A., Gatteschi, D. \& Lecomte C. (2001). New J. Chem. 1, 131-143.

Popelier, P. L. A. \& Bader, R. F. (1994). J. Phys. Chem. 98, 4473-4481. Rees, B. (1976). Acta Cryst. A32, 483-488.

Sanchez-Portal, D., Artacho, E. \& Soler, J. M. (1996). J. Phys. Condens. Matter. 8, 3859-3880.

Sanchez-Portal, D., Ordejon, P., Artacho, E. \& Soler, J. M. (1997). Int. J. Quant. Chem. 65, 453-461.

Sankey, O. F. \& Niklewski, D. J. (1989). Phys. Rev. B, 40, 3979-3995. Sheldrick, G. M. (1990). Acta Cryst. A46, 467-473.

Sheldrick, G. M. (1997). SHELXL97. University of Göttingen, Germany.

Souhassou, M. \& Blessing, R. H. (1999). J. Appl. Cryst. 32, 210-217. Souhassou, M., Lecomte, C., Blessing, R. H., Aubry, A., Rohmer, M. M., Wiest, R. \& Bénard, M. (1991). Acta Cryst. B47, 253-266.

Souhassou, M., Lecomte, C., Ghermani, N.-E., Rohmer, M.-M., Wiest, R., Bénard, M. \& Blessing, R. H. (1992). J. Am. Chem. Soc. 114, 2371-2382.

Stenkamp, R. E. \& Jensen, L. H. (1974). Acta Cryst. B30, 1541-1545. Stewart, R. F., Davidson, E. R. \& Simpson, W. T. (1965). J. Chem. Phys. 43, 175-187. 


\section{research papers}

Szabó, D., Kapovits, I., Argay, Gy., Czugler, M., Kalman, A. \& Koritsanszky, T. (1997). J. Chem. Soc. Perkin. Trans. 2, pp. 10451053.

Troullier, N. \& Martins, J. L. (1991). Phys. Rev. B, 43, 1993-2006.
Volkov, A., Abramov, Y., Coppens, P. \& Gatti, C. (2000). Acta Cryst. A56, 332-339.

Wiest, R., Pichon-Pesme, V., Bénard, M. \& Lecomte, C. (1994). J. Phys. Chem. 98, 1351-1362. 